\title{
Aplicação da compartimentação fisiográfica e da abordagem multitemática para elaboração de mapa geoambiental: estudo de caso nos municípios de Espírito Santo do Pinhal e Santo Antônio do Jardim (SP)
}

\author{
Physiographic compartmentation and multithematic analysis applied to development \\ geoenvironmental map: a case study in Espírito Santo do Pinhal and Santo Antonio do \\ Jardim, São Paulo State, Brazil
}

\author{
Camila Jardinetti Chaves ${ }^{1}$, Fábio Augusto Gomes Vieira Reis², Lucilia do Carmo Giordano², \\ Ana Maria Carrascosa do Amaral ${ }^{3}$, Claudia Vanessa dos Santos Corrêa ${ }^{3}$ \\ 'Programa de Pós-graduação em Geociências e Meio Ambiente, Instituto de Geociências e Ciências Exatas - UNESP, \\ Campus de Rio Claro, Avenida 24-A, 1.515, CEP 13506-900, Rio Claro, SP, BR (camila.j.chaves@gmail.com) \\ 2Departamento de Geologia Aplicada, Instituto de Geociências e Ciências Exatas - UNESP, Rio Claro, SP, BR \\ (fabioreis@rc.unesp.br) \\ 3Universidade Estadual Paulista "Júlio de Mesquita Filho", Rio Claro, SP, BR (Icg@ecogeologia.com.br; \\ ana.eng.ambiental@hotmail.com; claudiageobrax@yahoo.com.br)
}

Recebido em 16 de junho de 2014; aceito em 25 de fevereiro de 2015

\begin{abstract}
Resumo
O presente artigo tem como objetivo apresentar os estudos desenvolvidos para elaboração de mapeamento geoambiental por meio do uso da compartimentação fisiográfica e da abordagem multitemática, envolvendo a correlação das unidades fisiográficas, o uso e ocupação da terra, a presença de áreas de preservação permanente e a carta de chuvas intensas médias. Foram estabelecidos os municípios de Espírito Santo do Pinhal e Santo Antônio do Jardim (SP) como área de estudo, que se localizam no limite entre a Bacia Sedimentar do Paraná e o embasamento cristalino em termos geológicos e entre o Planalto Atlântico, representado pela Serra da Mantiqueira e a Depressão Periférica, na Zona do Rio Mogi Guaçu. Trata-se de uma área conhecida pela complexa organização paisagística, onde há problemas relacionados a processos de dinâmica superficial, tais como: enchentes, inundações, erosão e movimentos de massa. Os estudos foram baseados na definição das unidades de compartimentação fisiográfica na proposta metodológica de Zaine (2011). Já para a definição da carta das unidades geoambientais, foi usada a abordagem multitemática pela correlação das unidades fisiográficas de uso e ocupação da terra, das áreas de preservação permanente e de chuvas intensas médias. Os pesos para correlação das cartas multitemáticas foram estabelecidos pelo uso do Analytic Hierarchy Process (AHP) [Processo de Análise Hierárquica]. Pode-se concluir, pelos resultados obtidos, que a sequência metodológica usada na presente pesquisa pode ser desenvolvida com produtos cartográficos e imagens de uso público, sendo ideal para a utilização de municípios de pequeno e médio porte, pois apresenta custo baixo e tem aplicação relativamente fácil.
\end{abstract}

Palavras-chave: Análise integrada; Abordagem multitemática; Mapa geoambiental; Processos geológicos; SIG.

\begin{abstract}
This article aims to present the developed studies for preparation of geoenvironmental mapping through physiographic subdivision and multithematic analysis, involving the correlation of physiographic units, of the use and occupation of land, the presence of permanent preservation areas and the map of intense average rainfall. The study area comprises the municipalities of Espírito Santo do Pinhal and Santo Antônio do Jardim, São Paulo State, located at the boundary between the Sedimentary Basin of Paraná and the crystalline basement in geological terms, and between the Atlantic Plateau, represented by the Mantiqueira Mountain, and Peripheral Depression, in the Mogi Guaçu river zone. This is an area known for organizing complex landscape, where there are problems related to dynamic surface processes, such as floods, erosion and mass movements. The studies were based on the definition of the physiographic units by the Zane's methodological pro-
\end{abstract}


posal (2011). For the definition of the Map of Geoenvironmental Units, the multithematic analysis was used to correlate physiographic units, use and occupation of land, the permanent preservation areas and intense average rainfall. To correlate the weights of the thematic maps the Analytic Hierarchy Process (AHP) was used. It can be concluded from the results obtained that the methodological sequence used in this research can be developed with public cartographic products and images, being ideal for small and medium municipalities due to their low cost and relatively easiness of application.

Keywords: Integrated analysis; Multi thematic analysis; Geoenvironmental map; Geological process; GIS.

\section{INTRODUÇÃO}

Os recursos naturais desempenham um papel de grande importância para o desenvolvimento econômico e social, mas a utilização desordenada desses recursos e a acelerada expansão urbana sem planejamento têm gerado uma série de problemas ambientais. Essa situação é agravada no Brasil, principalmente, pela baixa escolaridade de sua população, pela descontinuidade nas políticas públicas de planejamento, pelo alto índice de população vivendo em áreas metropolitanas e pela desigualdade da distribuição de renda.

Por consequência, muitas cidades possuem uma considerável parcela da população vivendo em áreas de risco, imensas áreas agrícolas têm sido afetadas pela ocorrência de processos de dinâmica superficial e a pressão sobre a vegetação nativa e unidades de conservação tem aumentado.

Nesse sentido, é de grande importância considerar as características do meio físico, de forma a reconhecer suas potencialidades e fragilidades quanto ao uso da terra de acordo com suas condições naturais, buscando o apropriado desenvolvimento econômico do lugar. Dados sobre as potencialidades e restrições de uso da terra obtidos a partir do estudo geoambiental vêm se mostrando bastante eficientes como instrumento de planejamento ambiental, visando a análise e aprimoramento da interação existente entre o homem e o espaço geográfico, pela adequação das diferentes formas de ocupação do território.

Estudos como os de Vedovello e Mattos (1993, 1998), Oliveira et al. (1997), Giordano e Riedel (2008), Dewane Yamaguchi (2009), Li et al. (2010), Sparovek et al. (2010), Fernandes-da-Silva et al. (2010), Abreu e Augusto Filho (2011), Zaine (2011), entre outros, desenvolveram e aplicaram métodos para a elaboração de estudos de planejamento territorial.

Fiori (2004) ressalta que estão sendo desenvolvidas metodologias de mapeamento ou de ordenamento do território, como é o caso dos zoneamentos ambientais e geoambientais, com o objetivo de compartimentar o território com base nas características do geoambiente, suas inter-relações e relações com o meio biológico e com as atividades antrópicas, colocando em evidências as suas potencialidades ou restrições de uso.

Silva e Dantas (2010) e Zuquette e Gandolfi (2004) diferenciam basicamente duas linhas metodológicas principais para elaboração de mapas geoambientais: a abordagem analítica fundamentada na elaboração de mapas temáticos, com análise multicriterial em um enfoque geossistêmico, e a abordagem sintética baseada na avaliação de unidades homólogas por fotoanálise, com ênfase na informação geológica e fisiográfica.

Em relação à abordagem multitemática, Fiori (2004) destaca a importância das ferramentas de apoio técnico presentes na cartografia digital, Sistemas de Informações Geográficas (SIG) e Sensoriamento Remoto na correlação dos seguintes mapas temáticos: geológico, geomorfológico, pedológico, litológico, declividade, drenagem e do uso e ocupação da terra, integrando esses dados por métodos qualitativos (pela sobreposição de níveis de informação ou layers), matriciais (a partir de pesos são relacionados atributos e parâmetros do meio físico), probabilísticos (através de funções de probabilidades são relacionados atributos do meio físico) e determinísticos (no qual funções matemáticas são utilizadas na avaliação dos aspectos do meio físico).

Quanto ao enfoque sintético (análise integrada), Lollo (1998) e Vedovello et al. (2002) destacam que serão determinadas/delimitadas e caracterizadas as unidades do terreno ou fisiográficas a partir da análise das feições do relevo (landforms) pelas técnicas de fotointerpretação aplicadas em dados de sensoriamento remoto.

Nesse contexto, o presente estudo utiliza a análise integrada para estabelecer unidades fisiográficas do terreno com base na metodologia de fotoanálise desenvolvida por Zaine (2011), e a abordagem multitemática para integrar essas unidades fisiográficas com a carta de uso e cobertura da terra, de chuvas intensas e de áreas de preservação permanente, com o objetivo de elaborar Carta de Unidades Geoambientais na escala 1:50.000.

A área escolhida para desenvolvimento do estudo foi os municípios de Espírito Santo do Pinhal e Santo Antônio do Jardim (SP) devido a suas características geomorfológicas e geológicas, que se localizam no limite entre a Bacia Sedimentar do Paraná e o embasamento cristalino e as províncias geomorfológicas do Planalto Atlântico e a Depressão Periférica. Além desses aspectos, tratam-se de municípios de pequeno porte que não possuem instrumentos de gerenciamento territorial, situação muito recorrente nos municípios brasileiros, que necessitam de metodologias de baixo custo e de fácil aplicação. 


\section{ÁREA DE ESTUDO}

Espírito Santo do Pinhal e Santo Antônio do Jardim são municípios vizinhos, localizados no nordeste do estado de São Paulo, na mesorregião de Campinas, que fazem divisa com o sul do estado de Minas Gerais, estando situados na bacia hidrográfica do rio Mogi Guaçu, conforme ilustra a Figura 1.

Espírito Santo do Pinhal encontra-se na latitude -22 $2^{\circ} 1{ }^{\prime} 27^{\prime \prime}$ sul e longitude $-46^{\circ} 44^{\prime} 27^{\prime \prime}$ 'oeste, com área de $389,421 \mathrm{~km}^{2}$ e altitude aproximada de $870 \mathrm{~m}$, com uma população de 41.907 habitantes. Santo Antônio do Jardim está localizado nas proximidades das coordenadas geográficas de $-22^{\circ} 06^{\prime \prime} 57^{\prime}$ 'sul e $-46^{\circ} 40^{\prime \prime} 48^{\prime}$ oeste, com área de $110 \mathrm{~km}^{2} \mathrm{e}$ altitude média de $850 \mathrm{~m}$. Sua população é de 5.943 habitantes. Na região são encontrados vestígios do bioma Cerrado e Mata Atlântica (IBGE, 2010).

Em termos geomorfológicos, a área de estudo enquadrase, segundo o Mapa Geomorfológico do Estado de São Paulo (IPT, 1981a) e Ross e Moroz (1997), em duas províncias geomorfológicas. A Depressão Periférica (zona do Mogi-Guaçu) é uma província composta por relevo uniforme de colinas onduladas. Sua altitude mais elevada atinge em torno de $750 \mathrm{~m}$; já as menores cotas são de $600 \mathrm{~m}$, nas proximidades do Rio Oriçanga.
A outra província está relacionada à subunidade Planalto da Serra Negra/Lindoia (região serrana) no contexto Planalto Atlântico e é caracterizada por sua topografia mais marcante, composta predominantemente por morros com topos aguçados ou convexos e vertentes com perfis convexos e retilíneos, o chamado Mar de Morros, definido pela presença das serras cristalinas de terrenos pré-cambrianos. A região possui baixa coesão do saprólito, rampas médias e longas e relevo acidentado, características que favorecem a ocorrência de processos erosivos como erosão laminar e movimentos de massa (Ross, 1995).

Segundo Azevedo e Massoli (1984), "a delimitação das formas de relevo não compreende exatamente ao limite entre a bacia sedimentar e o cristalino", onde nas proximidades desse limite a topografia do embasamento cristalino apresenta-se com altitudes que chegam a $800 \mathrm{~m}$, ou seja, pouco acentuada. Sendo que em direção a leste e sudeste, a topografia do cristalino torna-se mais elevada.

Quanto à geologia, está representada principalmente pelo Maciço Guaxupé, com terrenos de alto grau metamórfico, e pelo Complexo Varginha, formado por rochas cristalinas do Grupo Pinhal. Dentro desse contexto, ocorre um vasto terreno granítico-gnáissico e diferentes migmatitos que possuem estruturas

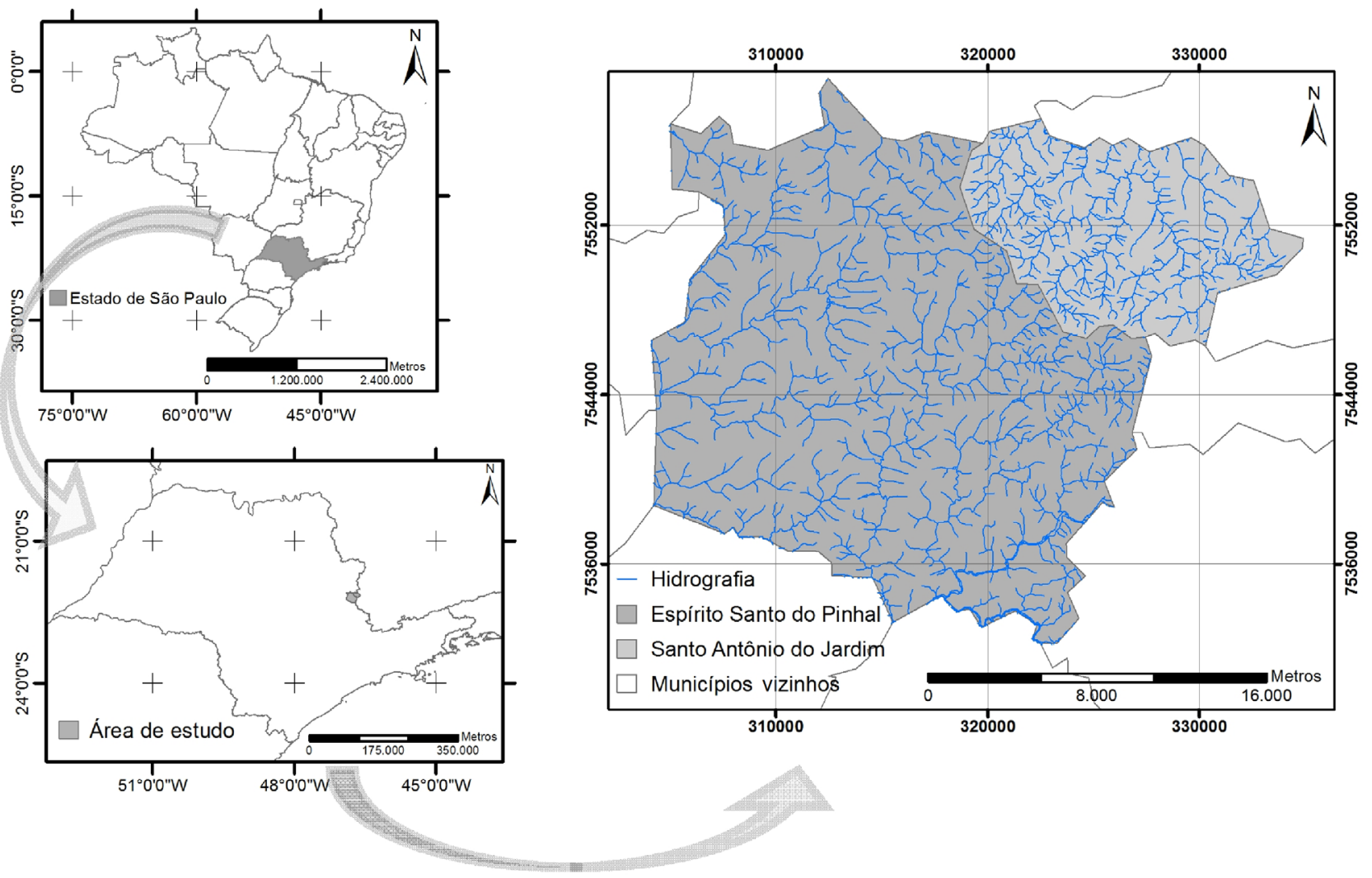

Figura 1. Localização da área de estudo. 
heterogêneas e homogêneas, contendo núcleos anatexíticos e granitoides porfiríticos a equigranulares (IPT,1981b).

\section{MATERIAIS E MÉTODOS}

\section{Materiais}

Para a elaboração do presente trabalho foram utilizados os seguintes materiais: imagens do satélite Landsat5 (sensor TM) referentes a data 28/09/2011, com resolução espacial de $30 \mathrm{~m}$, localizadas na latitude -21.7 e longitude -46.2 ; Folha Geológica de Aguaí, escala 1:50.000 (IG, 1983), Mapa Geológico do Estado de São Paulo, escala 1:500.000 (IPT, 1981a) e Mapa Geomorfológico do Estado de São Paulo, escala 1:1.000.000 (IPT, 1981b); folhas topográficas 1:50.000, disponibilizadas pelo Instituto Brasileiro de Geografia e Estatística (IBGE): folha Aguaí SF-23-Y-A-III-1, folha Águas de Lindoia SF-23-Y-A-III-4, folha Mogi-Guaçu SF-23-Y-A-III-3 e a folha Pinhal SF-23-Y-A-III-2 (IBGE, 1972a, 1972b, 1972c, 1972d); software de tratamento digital de imagens $\operatorname{Arc} G I S ® 10$ e equipamentos de apoio ao campo, como GPS, máquina fotográfica e fichas descritivas para os atributos fisiográficos constatados.

\section{Método e etapas da pesquisa}

\section{$1^{a}$ etapa:edição da base cartográfica}

Inicialmente, foi feito o georreferenciamento das quatro folhas topográficas a partir de quatro pontos de controle com erro menor que $1 \mathrm{~m}$ e determinadas com a projeção Universal Transversa de Mercator (UTM) e do Datum WGS84 (World Geodetic System 1984), zona 23. Posteriormente, foram vetorizadas as curvas de nível, cidades, hidrografia, divisa de municípios e rodovias.

Após a vetorização, foi possível obter o Modelo Digital de Elevação do Terreno (MDET) com grade triangular, pois representa melhor relevos complexos por meio de curvas de nível e hidrografia. Isto tornou possível a elaboração da carta hipsométrica, dividida a partir das linhas de quebra do relevo fundamentado nas curvas de nível, com altitudes em intervalos de $100 \mathrm{~m}$, determinadas em oito classes pelo método manual de: $600 \mathrm{~m}, 700 \mathrm{~m}, 800 \mathrm{~m}, 900 \mathrm{~m}, 1.000 \mathrm{~m}$, $1.100 \mathrm{~m}, 1.200 \mathrm{~m}$ e $1.300 \mathrm{~m}$.

A carta de declividade foi elaborada de acordo com os trabalhos realizados por De Biasi (1970), Lepsh et al. (1983) e Ross (1995) com os intervalos de 0 a 5\%, 5 a 12\%, 12 a $30 \%$ e maiores que $30 \%$. A carta de curvatura vertical foi produzida para definir as formas das encostas. Valeriano (2008) define a curvatura vertical de vertentes, com alto poder de identificação de unidades homogêneas do relevo, como estudos de compartimentação fisiográfica por ser um tipo de análise com forte relação com o tipo de substrato e com os processos de formação do relevo. A documentação cartográfica relacionada à geologia e à geomorfologia da região também foi georreferenciada e utilizada para consulta e apoio durante a caracterização da área e para desenvolvimento da compartimentação fisiográfica.

\section{$2^{a}$ etapa: análise integrada - compartimentação fisiográfica}

Para a compartimentação, foram utilizadas imagens do Landsat TM 5, resolução espacial de $30 \mathrm{~m}$. Elas foram importadas e analisadas em várias composições falsas cor e normalização dos níveis de cinza para dados de reflectância, de forma a identificar a banda que melhor representava as feições do relevo. A banda 5 também foi utilizada por Ferreira e Penteado (2011), Florenzano (1998) e Lousada e Campos (2005) para a compartimentação fisiográfica. Em seguida, essa banda foi georreferenciada com oito pontos de controle, e para melhor análise dos vários aspectos texturais, foi aplicado o contraste linear, os tons de cinzas sendo distribuídos e alterados, os ruídos presentes na imagem eliminada servindo de base para a delimitação das unidades, realizada em ambiente SIG, na escala 1:50.000.

Na delimitação das unidades fisiográficas, considerouse o método que pode ser dividido em três fases: a fotoleitura, a fotoanálise e, por último, a fotointerpretação a partir da análise integrada dos elementos do meio físico, baseado no trabalho de Soares e Fiori (1976):

(i) A fotoleitura representou o reconhecimento, em imagens de satélite, dos elementos que compõem a paisagem, considerando: bandas espectrais, resolução espacial e espectral, entre outras características.

(ii) $\mathrm{Na}$ fotoanálise, utilizou-se os quadros de análise elaborados por Zaine (2011), representado na (Figura 2) e critérios analíticos complementares para a compartimentação, desenvolvidos por IPT (1981a), conforme apresentado na Tabela 1.

(iii) A fotointerpretação fundamentou-se na identificação dos alvos na superfície terrestre e na caracterização das unidades compartimentadas pela função e relação dos objetos presentes na imagem de satélite.

A delimitação das unidades foi complementada a partir de análises sobre as cartas de hipsometria, declividade e curvatura vertical (perfil das vertentes), de forma a identificar conjuntos de sistemas de relevo, como pode ser observado na Tabela 1.

Destaca-se que durante todo o procedimento metodológico foi feita a integração das informações do contexto regional aos compartimentos, relacionados aos mapas de domínios geológicos e geomorfológicos, coletados na primeira fase da pesquisa. 
A partir da compartimentação fisiográfica prévia realizada, foram feitos levantamentos de campo, de forma a conferir a homogeneidade, similaridade e limites das unidades. Os pontos foram selecionados com base na necessidade de se obter informações de cada unidade compartimentada. Nas observações in situ foram considerados os materiais geológicos expostos nos cortes das estradas percorridas e em afloramentos naturais, sendo registradas em fichas descritivas que continham os seguintes itens: tipo de solo, relevo, material rochoso, perfil de alteração e processos geológicos de forma a subsidiar o uso da terra. Posteriormente, os dados coletados em campo foram integrados a carta de compartimentação fisiográfica e ao quadro descritivo das unidades para complementação das informações.

\section{$3^{a}$ etapa: abordagem multitemática para} elaboração da carta de unidades geoambientais

Para o desenvolvimento da abordagem multitemática, além da carta de unidades fisiográficas, foi necessário desenvolver outras cartas, sem essencialmente compor padrões da fisionomia do terreno. Neste caso, a carta de uso e cobertura da terra, carta de chuvas intensas médias (representando as médias de precipitação dos meses mais chuvosos) e a carta de áreas de preservação permanente.

Para cada carta que compõe a análise multicriterial foram atribuídas cinco classes de zoneamento, o peso 1 correspondendo a classe de mais baixa suscetibilidade aos processos do meio físico e o peso 5 representando a classe de mais alta suscetibilidade a ocorrência desses processos.

Para a carta de compartimentação fisiográfica, os critérios para a definição da ponderação dos cinco pesos basearam-se em Ross (1995) e Pilachevsky (2013), conforme apresentado na Tabela 2.

A elaboração da carta de uso e cobertura das terras da área de estudo foi realizada a partir da classificação de forma não automática, ou seja, classificação visual pela interpretação dos alvos em uma composição de acordo com o comportamento espectral das classes contidas nas imagens de satélite do Landsat TM 5, nas composições coloridas R3 G4 B5. Para que houvesse maior precisão sobre os limites das classes e no contexto atual da área de estudo, foi preciso importar polígonos extraídos de imagens de alta resolução atualizadas e coloridas contidas no programa de computador Google Earth versão gratuita.

Para a verificação da precisão dessa carta, foi adotada a técnica desenvolvida por Valeriano (1985), denominada de verificação da estimativa de exatidão da classificação de cartas temáticas, com base nos trabalhos de Ginevan (1979) e Genderen (1977), sendo considerado primeiramente o tamanho da amostra (quantidade de pontos amostrais a serem analisados em campo). A partir dessa técnica a carta de uso e cobertura da terra foi classificada com exatidão de $0,94 \%$.
A Tabela 3 representa as classes atribuídas à carta de uso e cobertura da terra e a respectiva ponderação usada na integração para elaboração da carta de unidades geoambientais.

As informações sobre as chuvas intensas médias foram obtidas no "site" do Sistema de Informações para o Gerenciamento de Recursos Hídricos do Estado de São Paulo (SigRH). São dados de grande importância para a melhor compreensão do modelamento e a intensidade dos processos geológicos quanto às formas superficiais da área de estudo, sendo a precipitação um dos principais eventos responsáveis por enchentes, inundações, erosão e movimentos de massa.

Para a elaboração da carta de chuvas intensas médias foram coletados dados de séries históricas de 57 pluviômetros localizados em Espírito Santo do Pinhal e Santo Antônio do Jardim e entorno. Registros relacionados aos meses mais chuvosos, de dezembro a março, foram inseridos em uma planilha do Excel, e assim exportados para o $A r c G i s$, no qual esses vértices foram visualizados pela ferramenta Display XY Data e foram convertidos para o formato shapefile de pontos pelo Export Data, contendo os valores médios de precipitação, possibilitando a visualização da distribuição dos 57 pluviômetros. A partir da ferramenta Topo to Raster interpolou-se essa superfície com os dados de chuva média, sendo os valores gerados e classificados em cinco classes pelo método Natural Breaks (Jenks). A divisão das classes de suscetibilidade a chuvas intensas estão apresentas na Tabela 4.

Por último, foram consideradas as classes relacionadas às Áreas de Preservação Permanente (APP) com restrição segundo Novo Código Florestal - Lei Federal n ${ }^{\circ}$ 12.651/2012 (Brasil, 2012), para a delimitação das APP ao longo dos cursos d'água, nascentes e topo de morros, montes, montanhas e serras.

Com a elaboração das cartas de Compartimentação Fisiográfica, Uso e Cobertura da Terra, Chuvas Intensas Médias e Áreas de Preservação Permanente, foi possível reconhecer os valores de prioridades de cada uma através do método de Analytic Hierarchy Process (AHP) [Processo de Análise Hierárquica] desenvolvido por Saaty (1980), na qual cada carta recebeu um peso de importância para a sobreposição ponderada.

Nas Tabelas 5, 6 e 7 estão presentes os julgamentos paritários e o autovetor para os atributos que compuseram a carta geoambiental.

A partir de então obteve-se os autovetores, que apresentam a ordem de prioridade dos atributos, onde a compartimentação fisiográfica aparece como fator mais importante $(55,79 \%)$, contendo informações morfoambientais e genéticas das unidades e seu comportamento perante as atividades antrópicas; em seguida, a carta de Áreas de Preservação Permanente (20,67\%), ambientalmente frágeis e vulneráveis; e, por último, as cartas de Chuvas Intensas Médias (17,85\%) 


\begin{tabular}{|c|c|c|c|c|}
\hline \multicolumn{2}{|c|}{ 1. Análise da densidade textural } & \multicolumn{3}{|c|}{ CLASSES } \\
\hline $\begin{array}{l}\text { Elementos de } \\
\text { análise }\end{array}$ & Elementos de drenagem e relevo & & & \\
\hline \multirow{2}{*}{$\begin{array}{l}\text { Critérios de } \\
\text { análise }\end{array}$} & $\begin{array}{l}\text { Densidade dos elementos de } \\
\text { drenagem }\end{array}$ & Baixa $\left(0\right.$ a $\left.5 / 10 \mathrm{~km}^{2}\right)$ & Média (5 a 30/10 km²) & $\begin{array}{l}\left.\mathrm{km}^{2}\right) \\
4 k\end{array}$ \\
\hline & $\begin{array}{l}\text { Densidade dos elementos do } \\
\text { relevo (dissecação e rugosidade } \\
\text { do terreno) }\end{array}$ & 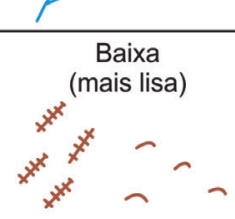 & 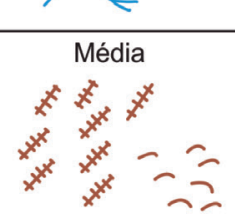 & $\begin{array}{c}\text { Alta } \\
\text { (mais rugosa) }\end{array}$ \\
\hline \begin{tabular}{|l|}
$\begin{array}{l}\text { Propriedade a ser } \\
\text { interpretada }\end{array}$ \\
\end{tabular} & Permeabilidade (intergranular) & $\begin{array}{c}\text { Alta } \\
\text { (Permeável) }\end{array}$ & Média & $\begin{array}{c}\text { Baixa } \\
\begin{array}{c}\text { (Pouco perménel a } \\
\text { impermeavel) }\end{array} \\
\end{array}$ \\
\hline \multirow{2}{*}{$\begin{array}{l}\text { Aplicações } \\
\text { Informaçoes interpre- } \\
\text { tadas por esta análise }\end{array}$} & Relação escoamento superficial/infiltração & Baixa & Média & Alta \\
\hline & Espessura e caracteristicas do manto de alteração & $\begin{array}{c}\text { Grande } \\
\text { (Espesso; }>5 \mathrm{~m} \text { ) }\end{array}$ & Média & $\begin{array}{c}\text { Pequena } \\
\text { (Raso/rocha aflorante) }\end{array}$ \\
\hline
\end{tabular}

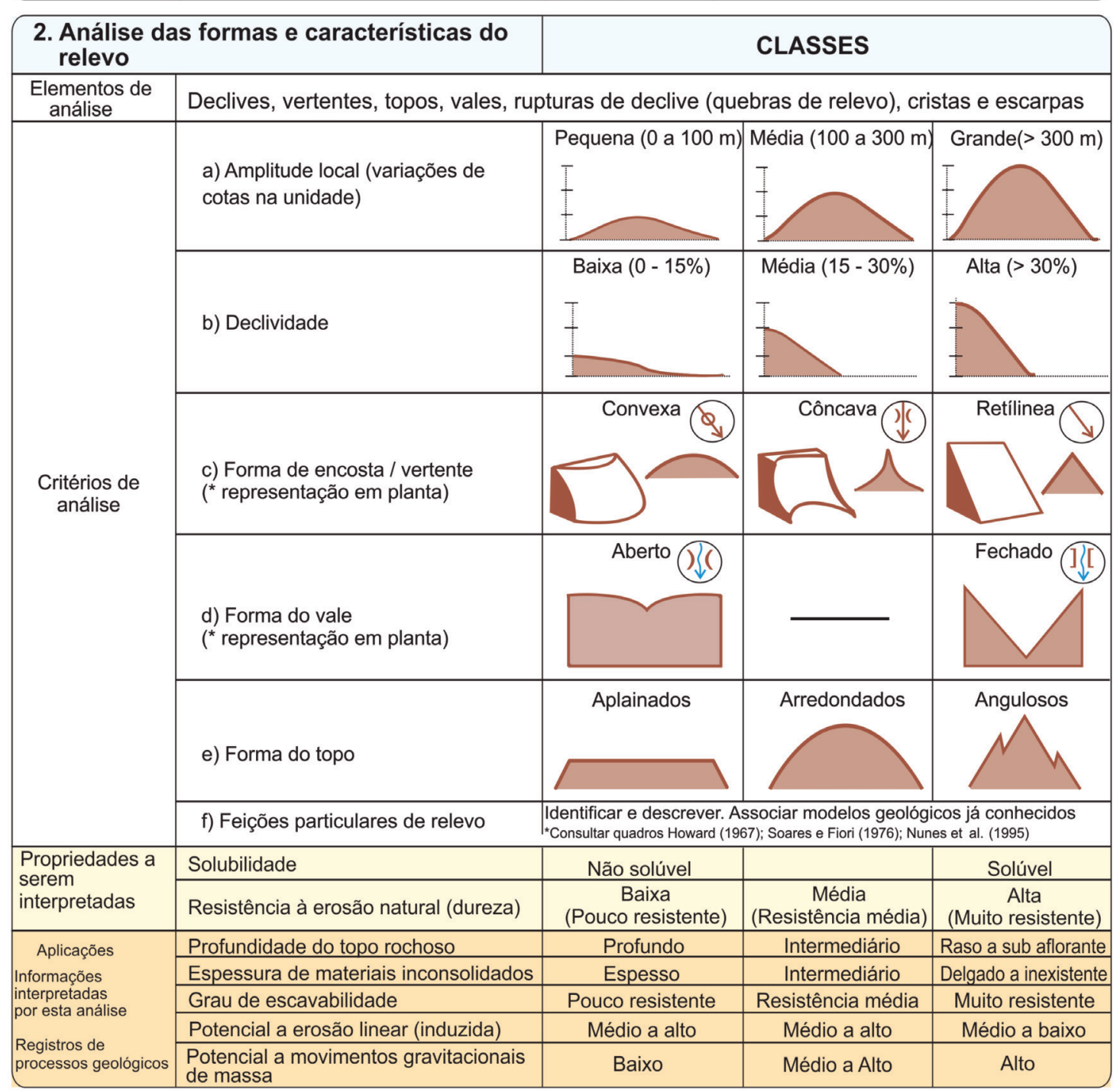

Fonte: Zaine (2011).

Figura 2. Análise geológica nas imagens de sensoriamento remoto. (continua...) 


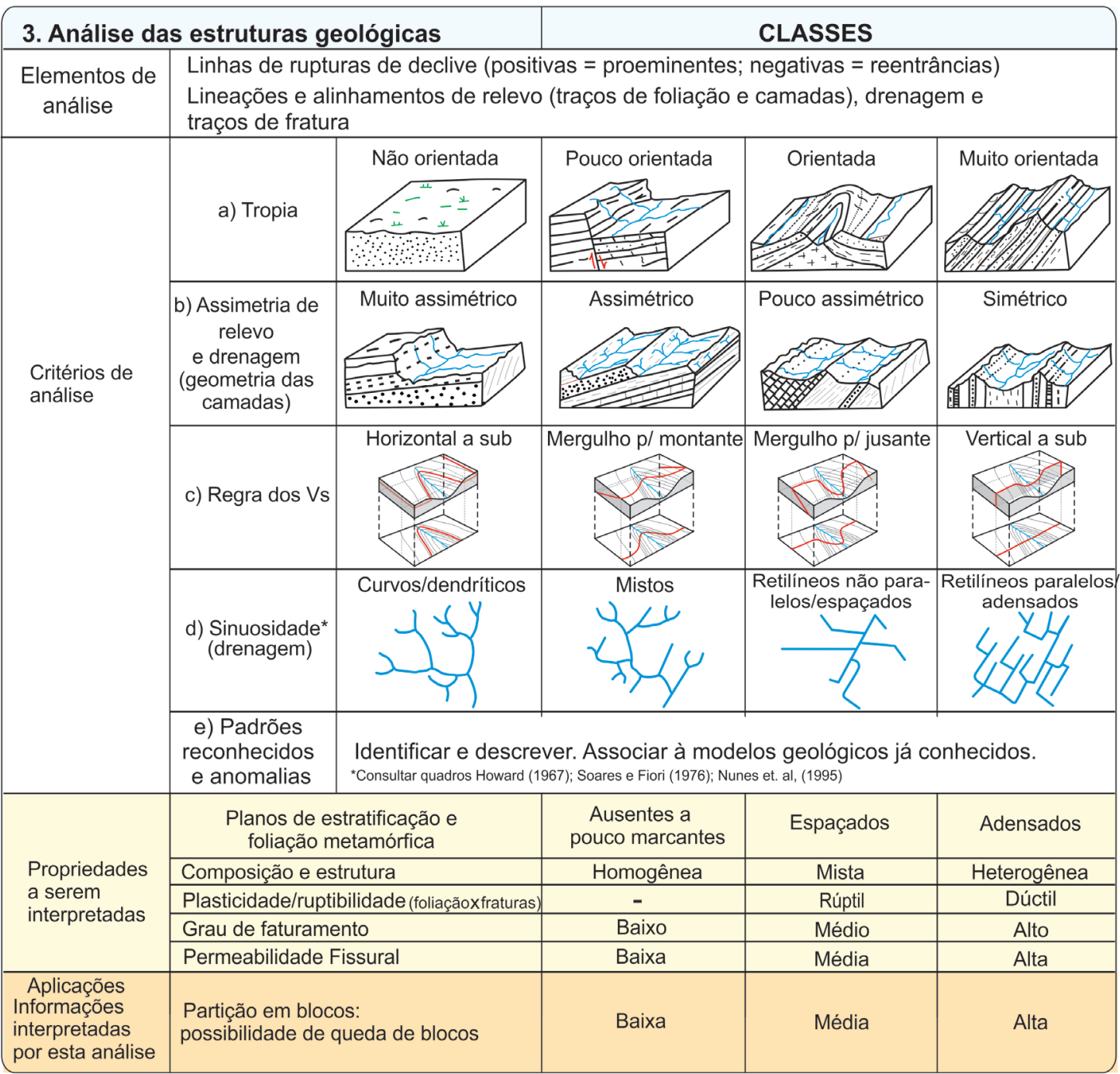

\begin{tabular}{|c|c|c|c|c|}
\hline \multicolumn{2}{|c|}{ 4. Análise complementar } & \multicolumn{3}{|c|}{ CLASSES } \\
\hline $\begin{array}{l}\text { Elementos de } \\
\text { análise }\end{array}$ & \multicolumn{4}{|c|}{ Tons de cinza ou coloração; vegetação e uso do solo; feições de processos geológicos } \\
\hline \multirow{2}{*}{$\begin{array}{l}\text { Critérios de } \\
\text { análise }\end{array}$} & Tons de cinza * & branco a cinza claro & cinza médio & cinza escuro a preto \\
\hline & Coloração* & Claros, amarelados, róseos & & $\begin{array}{c}\text { Verdes escuros } \\
\text { a pretos }\end{array}$ \\
\hline \multirow{3}{*}{$\begin{array}{l}\text { Propriedades } \\
\text { a serem } \\
\text { interpretadas }\end{array}$} & $\begin{array}{l}\text { Solos derivados de rochas básicas/ácidas } \\
\text { ou arenosas/argilosas }\end{array}$ & Solos ácidos/ arenosos & Solos básicos/argilosos & \\
\hline & Presença de água/umidade no solo & Solos secos & Solos úmidos & Corpos d'água** \\
\hline & Cobertura vegetal & $\begin{array}{c}\text { Sem vegetação a } \\
\text { pastagem }\end{array}$ & Rasteiras e arbustivas & $\begin{array}{c}\text { Arbóreas (florestas e } \\
\text { reflorestamento) }\end{array}$ \\
\hline \multirow{3}{*}{$\begin{array}{l}\text { Aplicações } \\
\text { Informações } \\
\text { interpretadas } \\
\text { por esta } \\
\text { análise }\end{array}$} & Solo exposto & Presente & & Ausente \\
\hline & Afloramentos e blocos rochosos & Presente & & Ausente \\
\hline & Presença de N.A. raso/aflorante & $\begin{array}{l}\text { Profundo } \\
(>5 \mathrm{~m})\end{array}$ & Variável & $\begin{array}{c}\text { Raso } \\
\text { (aflorante }<2 \mathrm{~m} \text { ) }\end{array}$ \\
\hline
\end{tabular}

${ }^{*}$ A análise deve considerar os diferentes tipos de uso do solo.

** Corpos d'água podem apresentar tons claros quando ocorre a reflexão da luz.

Fonte: Zaine (2011).

Figura 2. Continuação. 
Tabela 1. Critérios analíticos utilizados na compartimentação fisiográfica.

\begin{tabular}{|c|c|c|c|}
\hline Critério & Categoria & Intervalo & Conceito \\
\hline $\begin{array}{l}\text { Amplitude } \\
\text { Local }\end{array}$ & $\begin{array}{l}\text { Pequena } \\
\text { Média } \\
\text { Grande }\end{array}$ & $\begin{array}{l}0-100 \mathrm{~m} \\
100-300 \mathrm{~m} \\
>300 \mathrm{~m}\end{array}$ & $\begin{array}{c}\text { Altura máxima da unidade } \\
\text { em metros, acima do } \\
\text { assoalho dos grandes vales } \\
\text { adjacentes }\end{array}$ \\
\hline Declividade & $\begin{array}{l}\text { Baixa } \\
\text { Média } \\
\text { Alta }\end{array}$ & $\begin{array}{c}0-15 \% \\
15-30 \% \\
>30 \%\end{array}$ & $\begin{array}{l}\text { Inclinação média do perfil da } \\
\text { encosta }\end{array}$ \\
\hline Densidade de Drenagem & $\begin{array}{l}\text { Baixa } \\
\text { Média } \\
\text { Alta }\end{array}$ & $\begin{array}{l}0-05 \\
5-30 \\
30\end{array}$ & $\begin{array}{l}\text { Número de cursos d'água } \\
\text { perenes numa área de } \\
10 \mathrm{~km}^{2}\end{array}$ \\
\hline Topos & $\begin{array}{l}\text { Extensos } \\
\text { Restritos }\end{array}$ & - & Convencional \\
\hline $\begin{array}{l}\text { Formas } \\
\text { de Topos }\end{array}$ & $\begin{array}{l}\text { Aplainados } \\
\text { Arredondados } \\
\text { Angulosos }\end{array}$ & - & Convencional \\
\hline Perfil das Vertentes & $\begin{array}{l}\text { Convexo } \\
\text { Retilíneo } \\
\text { Côncavo }\end{array}$ & - & Convencional \\
\hline
\end{tabular}

Fonte: IPT (1981a).

e de Uso e Cobertura da Terra com (5,69\%), representando os principais agentes intensificadores dos processos geológicos. De acordo com o método AHP, o resultado foi consistente, já que a Razão de Consistência (RC) foi menor que 10\%.

Em seguida, foi empregado o procedimento proposto por Ross (1995) e Bennet e Doyle (1997), no qual essas cartas foram convertidas em dados rasters para a sobreposição ponderada pela ferramenta Weighted overlay, disponível no software Arc Gis 10. As camadas foram reclassificadas numa escala de 1 a 9 em números inteiros e ponderadas com peso de importância em porcentagem.

Por meio do método de ponderação, foi obtida a divisão de unidades homogêneas conforme as potencialidades e suscetibilidade do terreno a ocorrência de processos do meio físico relacionados aos principais processos de dinâmica superficial (assoreamento, erosão, movimentos de massa, enchentes e inundações).

A seguir são apresentadas as cartas de compartimentação fisiográfica (Figura 3), áreas de preservação permanente (Figura 4), chuvas intensas médias (Figura 5) e uso e cobertura da terra (Figura 6).

\section{RESULTADOS}

A ponderação resultou em sete unidades geoambientais de acordo com as fragilidades e potencialidades do terreno. A seguir são descritas as características principais de cada unidade:

\section{Unidade geoambiental A}

Apresenta rochas intrusivas básicas, latossolo vermelho do tipo argiloso e terreno formado por colinas com topos aplainados. Quanto ao uso da terra, essa unidade apresenta intensa atividade agrícola, onde há a presença de $33 \%$ de culturas temporárias, relacionada principalmente ao cultivo de cana de açúcar, seguidas pelos cultivos permanentes, como a silvicultura $(27 \%)$ e a pastagem $(21 \%)$.

O processo geológico pertinente nesta unidade é a erosão ao longo de estradas não pavimentadas em pontos isolados, especialmente em pequenos taludes e devido ao inadequado manejo de áreas agrícolas, principalmente as áreas ocupadas por pastagem e cultivos temporários. A suscetibilidade à ocorrência de eventos pluviométricos excepcionais é considerada muito baixa, podendo acumular em torno de 202,8 mm de água nos meses chuvosos.

Recomenda-se o adequado manejo das áreas agrícolas de forma a evitar erosões ao longo de estradas não pavimentadas e análises para a verificação de rochas e blocos aflorantes que podem impedir a instalação de determinados tipos de usos da terra, principalmente a mecanização em áreas agrícolas.

\section{Unidade geoambiental B}

Localizada a oeste da área de estudo, também é considerada com baixa suscetibilidade aos grandes eventos pluviométricos, composta por rochas do Grupo Itararé, arenitos finos 
Tabela 2. Critérios utilizados para a definição dos pesos para cada unidade fisiográfica.

Pesos

Principais características para a definição dos pesos

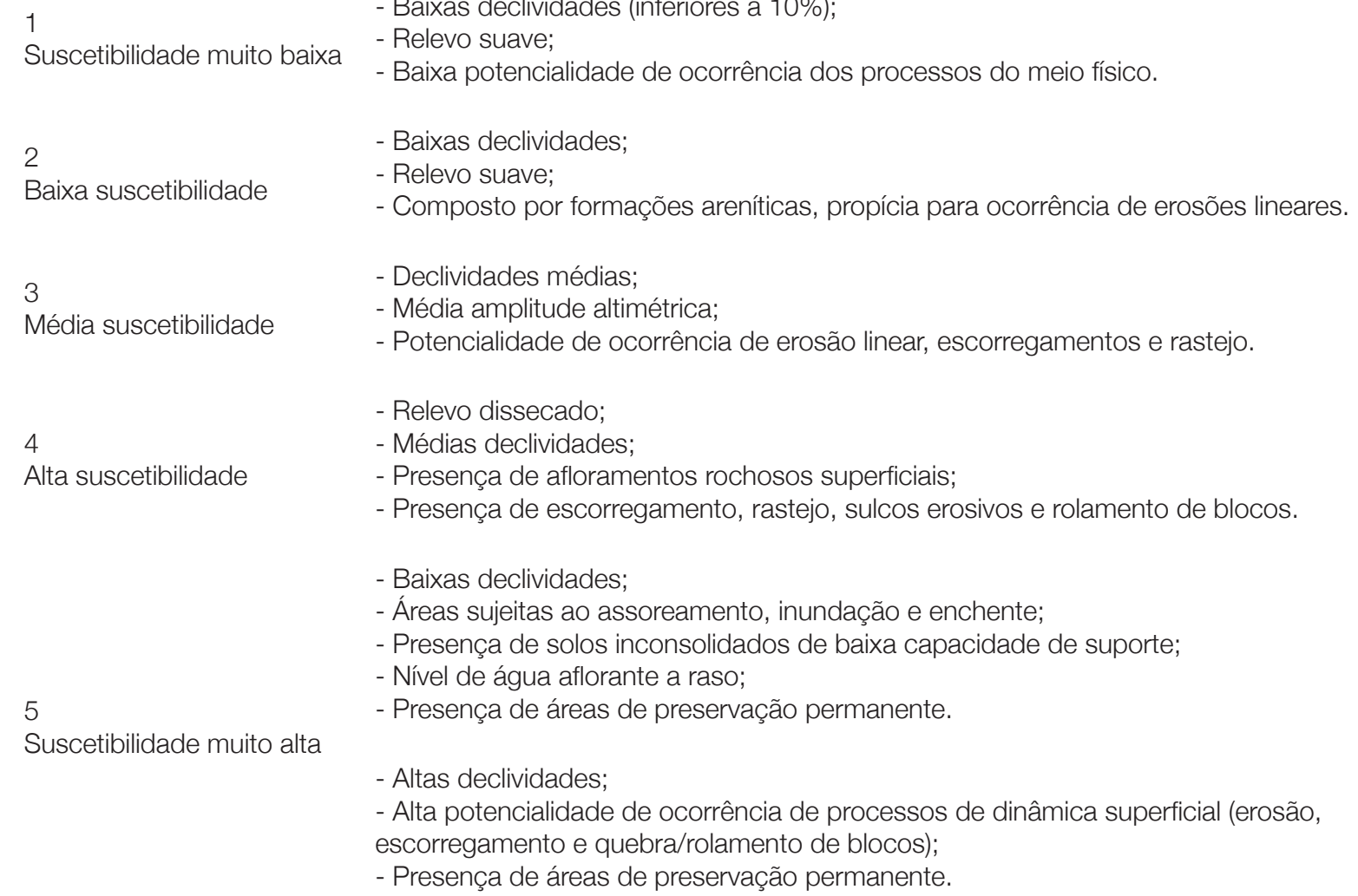

- Altas declividades;

- Alta potencialidade de ocorrência de processos de dinâmica superficial (erosão, escorregamento e quebra/rolamento de blocos);

- Presença de áreas de preservação permanente.

Fonte: Adaptado de Pilachevsky (2013).

Tabela 3. Classes de fragilidades estabelecidas no uso e cobertura da terra.

\begin{tabular}{lc} 
Peso das classes & Uso e cobertura da terra \\
\hline 1 & Vegetação arbórea \\
2 & \\
Fraca & Vegetação arbustiva \\
3 & Cultura permanente, área urbana, \\
Média & $\begin{array}{l}\text { edificações, gramínea, campo sujo } \\
\text { (planície aluvionar) e corpo d'água. } \\
4\end{array}$ \\
Forte & Cultura temporária, pastagem e \\
5 & distrito industrial. \\
Muito forte & Solo exposto e mineração. \\
\hline
\end{tabular}

Tabela 4. Classe de suscetibilidade a chuvas intensas na área de estudo.

\begin{tabular}{lc} 
Peso das classes & Chuvas acumuladas \\
\hline 1 & $<202,8$ \\
Muito baixa & $202,8-220,0$ \\
2 & \\
Baixa & $220,0-237,2$ \\
3 & \\
Média & \\
4 & $237,2-254,4$ \\
Alta & \\
5 & $>271,6$ \\
Muito alta &
\end{tabular}

Fonte: Adaptado de Ross (1995) 
Tabela 5. Matriz AHP dos atributos utilizados na carta geoambiental: Matriz Recíproca.

\begin{tabular}{lcccc}
\hline Cartas & $\begin{array}{c}\text { Compartimentação } \\
\text { fisiográfica }\end{array}$ & $\begin{array}{c}\text { Chuvas intensas } \\
\text { médias }\end{array}$ & APPs & $\begin{array}{c}\text { Uso e cobertura } \\
\text { da terra }\end{array}$ \\
\hline Compartimentação fisiográfica & $1 / 1$ & $3 / 1$ & $5 / 1$ & $7 / 1$ \\
Chuvas intensas médias & $1 / 3$ & $1 / 1$ & $3 / 1$ & $5 / 1$ \\
APPs & $1 / 5$ & $1 / 3$ & $1 / 1$ & $3 / 1$ \\
Uso e cobertura da terra & $1 / 7$ & $1 / 5$ & $1 / 3$ & $1 / 1$ \\
Soma & $176 / 105$ & $68 / 15$ & $28 / 3$ & 16 \\
\hline
\end{tabular}

Tabela 6. Matriz Normalizada.

\begin{tabular}{|c|c|c|c|c|c|}
\hline Cartas & $\begin{array}{c}\text { Compartimentação } \\
\text { fisiográfica }\end{array}$ & $\begin{array}{c}\text { Chuvas intensas } \\
\text { médias }\end{array}$ & APPs & $\begin{array}{c}\text { Uso e cobertura } \\
\text { da terra }\end{array}$ & Autovetor \\
\hline $\begin{array}{l}\text { Compartimentação } \\
\text { fisiográfica }\end{array}$ & $105 / 176$ & $45 / 68$ & $15 / 28$ & $7 / 16$ & 0,5579 \\
\hline Chuvas intensas médias & $35 / 176$ & $15 / 68$ & $3 / 28$ & $3 / 16$ & 0,1785 \\
\hline APPs & $21 / 176$ & $5 / 68$ & $9 / 28$ & $5 / 16$ & 0,2067 \\
\hline Uso e cobertura da terra & $15 / 176$ & $3 / 68$ & $1 / 28$ & $1 / 16$ & 0,0569 \\
\hline Soma & 1 & 1 & 1 & 1 & 1 \\
\hline
\end{tabular}

a grosseiros e siltito, formando, principalmente, latossolos vermelho amarelo de textura areno-siltosa e, localmente, areno-argilosa, com perfis de alteração e nível de água subterrânea profundos, onde há a predominância de infiltração em relação ao escoamento superficial, sendo considerada uma área de recarga do aquífero Itararé.

De acordo com o uso e cobertura da terra, essa unidade pode ser dividida em duas subunidades geoambientais distintas, como pode ser observado nos próximos itens.

\section{Subunidade geoambiental B1}

É ocupada em torno de $43 \%$ por vegetação arbórea, 23\% por vegetação arbustiva e $15 \%$ por pastagem. Caracteriza

Tabela 7. Análise de erro.

\begin{tabular}{lll}
\hline$\lambda \max$ & 4,58 & \\
\hline$I C$ & 0,01 & \\
ICR & 0,90 & \\
RC & 0,02 & $2,16 \%$ \\
\hline
\end{tabular}

essa subunidade a presença de matas ao longo de algumas drenagens, que contribuem para sua proteção, tornando-a de baixa suscetibilidade aos processos do meio físico. Entretanto, em alguns trechos não ocorre esse tipo de cobertura, intensificando os processos relacionados ao assoreamento, erosão, enchentes e até mesmo inundações. Isso se deve a intensa pressão das atividades agrícolas no entorno, que avançam cada vez mais sobre as áreas com matas nativas.

Recomenda-se a preservação das matas ciliares e até mesmo a revitalização dessas áreas desmatadas a partir de planos de adequação ambiental previstos pela legislação e desenvolvidas nas propriedades rurais. Planos que prezam o manejo racional dos recursos naturais, tendo como objetivo conciliar o desenvolvimento econômico e a conservação do meio ambiente.

\section{Subunidade geoambiental B2}

Em relevo de morrotes, a subunidade B2 é composta, principalmente, pela cultura temporária (46\%) e culturas permanentes (45\%), sendo apenas $3 \%$ destinado à pastagem. Devido a sua formação arenítica e ao predomínio de 
culturas temporárias, essa subunidade geoambiental apresenta potencialidade aos processos erosivos, especialmente à erosão linear.

Com o objetivo de evitar esse processo recomenda-se o manejo adequado e a rotação de culturas. $\mathrm{O}$ controle da aplicação de fertilizantes e agrotóxicos deve ser redobrado, já que nesta subunidade ocorrem áreas de recarga do aquífero Itararé, com porosidade granular, sendo do tipo livre e semiconfinado, descontínuo, heterogêneo e anisotrópico (Lopes, 1994).

\section{Unidade geoambiental C}

Com uma representação espacial com mais de 22.000 ha, esta unidade compreende os terrenos com relevo de morros e morros paralelos, constituídos de rochas do Complexo Migmatítico-Granítico, com granitos finos a médios. São rochas pré-cambrianas do embasamento cristalino e média densidade de drenagem.

O uso da terra é destinado para as culturas temporárias $(28 \%)$, pastagens $(28 \%)$ e culturas permanentes $(20 \%)$. Nas áreas destinadas às pastagens e culturas permanentes, ocorre o uso intensivo dos meios de produção, especialmente da pecuária leiteira e da cafeicultura tradicional, respectivamente. Essas atividades, na maioria das vezes, estão associadas a impactos ambientais gerados pela falta de cobertura natural e o inadequado manejo das pastagens.

Essa unidade apresenta potencialidade para o desenvolvimento de rastejo e escorregamento circular em taludes em rodovias. Recomenda-se que nesta unidade geoambiental o uso da terra seja destinado à produção agrícola não mecanizada devido à grande concentração de matacões, sendo que a expansão urbana só seria possível acompanhada por um mapeamento de risco e a manutenção e monitoramento constantes das estruturas de contenção do processo de movimentos de massa.

\section{Unidade geoambiental D}

Com cerca de 13.300 ha, a unidade geoambiental D possui migmatitos de injeção, subordinamente anatexitos e granitoides porfiríticos, que geram solos do tipo arenoso e arenossiltoso, localmente, com granulometria grosseira, especialmente nos locais de ocorrência de granitoides porfiroides. Apresenta relevo de mar de morros com alta densidade de drenagem.

O uso dessa unidade é composto principalmente pela cultura temporária e permanente. Juntas representam $68 \%$ da área, pastagem (11\%), vegetação arbórea (7\%) e abrigando grande parte das áreas urbanas de Espírito Santo do Pinhal e Santo Antônio do Jardim (7\%). Essa unidade geoambiental foi considerada adequada para ocupação pelas declividades serem suaves e seu perfil de alteração espesso.

Verificam-se processos como rastejo, escorregamento em solo e sulcos erosivos em obras de talude, principalmente em rodovias. Recomendam-se obras preventivas de erosão em áreas de terraplenagem e aberturas de vias, além do levantamento detalhado das áreas de risco desses processos de instabilidade e a formulação de diretrizes para medidas de contenção e prevenção.

\section{Unidade geoambiental E}

A unidade geoambiental E, com aproximadamente 1.200 ha, ocupada basicamente por pastagens ( $74 \%$ da área), tem uma pequena porção da área urbana de Espírito Santo do Pinhal, e apresenta características que a tornam uma área inadequada à ocupação. Isso se dá pela presença de depósitos de tálus, que dificultam a execução de obras civis, especialmente fundações e mecanização agrícola.

É possível ocorrer movimentos de massa (rastejo, escorregamento e rolamento de blocos), o que a deixa com grande potencial à ocorrência desses processos de dinâmica superficial, que podem ser intensificados pelos eventos pluviométricos excepcionais. No período chuvoso pode acumular de 220 a $271 \mathrm{~mm}$ de água, dado que mostra a unidade geoambiental E com suscetibilidade de média a muito alta a chuvas intensas.

Dessa forma, recomenda-se que estudos detalhados com levantamento/mapeamento das áreas de risco a movimentos de massa sejam desenvolvidos, tendo como objetivo o planejamento territorial como medida preventiva.

\section{Unidade geoambiental F}

A unidade geoambiental $\mathrm{F}$ foi subdividida em duas, a F1e a F2, esta última relacionada essencialmente às áreas das planícies aluvionares. Ambas possuem alta suscetibilidade aos processos do meio físico, como erosão e movimentos de massa na F1 e assoreamento, inundação e enchente na F2.

\section{Subunidade geoambiental F1}

Representa terrenos com altas declividades e amplitude altimétrica, consequentemente com escoamento superficial alto e rochas aflorantes em área de topo de serra. Essa subunidade possui potencial para a ocorrência de movimentos de massa e erosão linear em áreas de média e baixa encosta, características que tornam essa subunidade inadequada à ocupação.

O uso e cobertura da terra são compostos, principalmente, pelas pastagens (36\%), culturas permanentes $(20 \%)$ e vegetação arbórea e arbustiva (34\%), sendo que essas duas últimas classes são os usos mais adequados para essa área, contribuindo na contenção dos processos de dinâmicas 

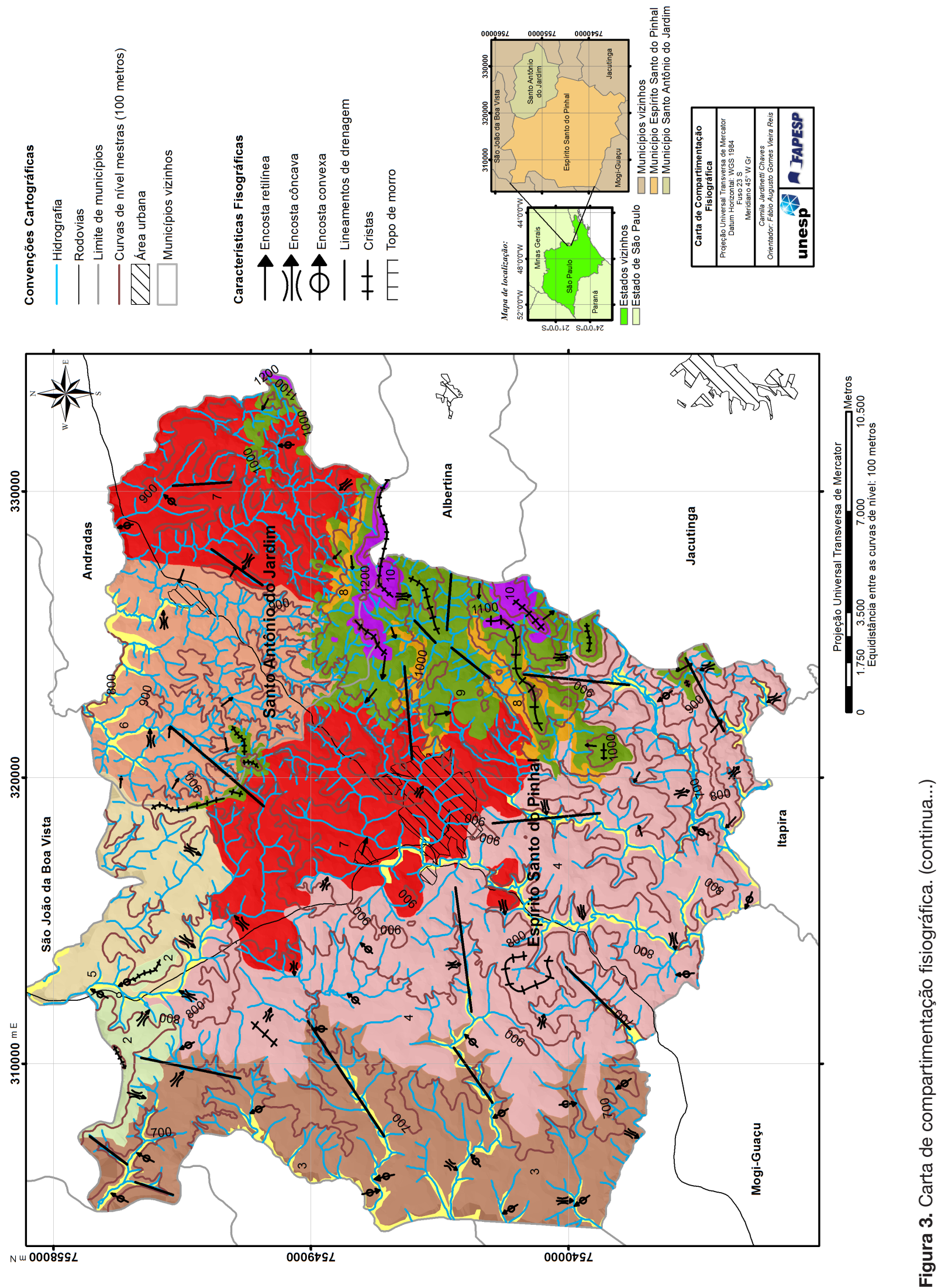


\begin{tabular}{|c|c|c|c|c|c|c|c|c|c|c|c|}
\hline \multirow{2}{*}{ 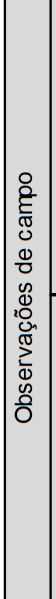 } & 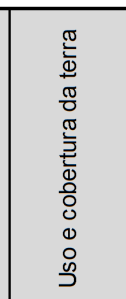 & 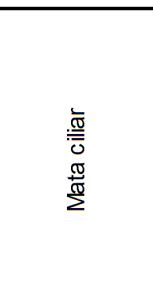 & 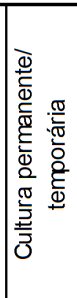 & 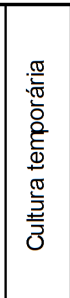 & 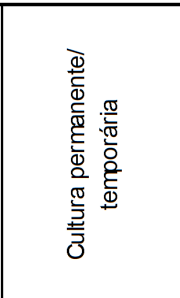 & 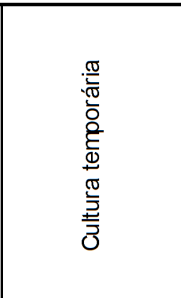 & 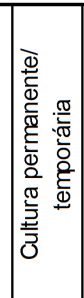 & 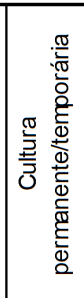 & 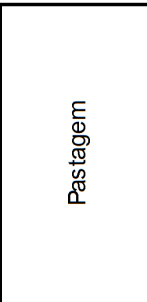 & 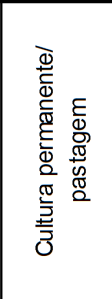 & 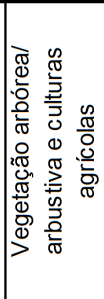 \\
\hline & 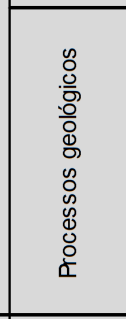 & 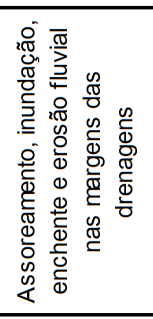 & 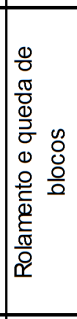 & 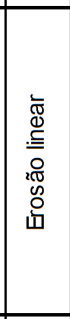 & 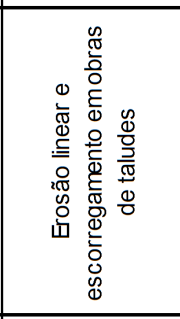 & 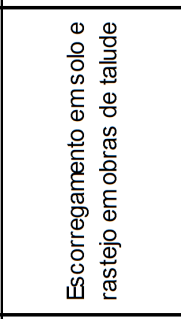 & 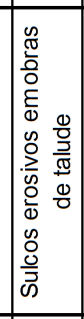 & 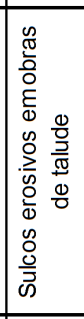 & 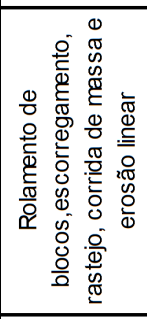 & 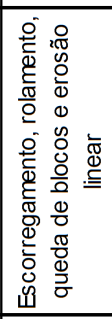 & 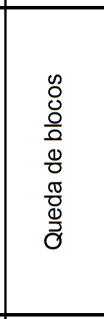 \\
\hline \multirow{2}{*}{ 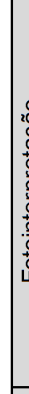 } & 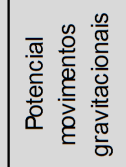 & $\begin{array}{l}\text { 음 } \\
\text { : }\end{array}$ & 咅 & 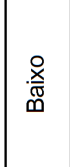 & 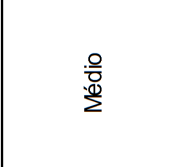 & $\begin{array}{l}\text { 응 } \\
\text { : }\end{array}$ & $\begin{array}{l}\frac{0}{0} \\
\frac{0}{0.0} \\
\frac{0}{0} \\
\frac{00}{2}\end{array}$ & 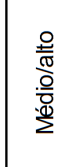 & $\frac{\stackrel{\circ}{4}}{4}$ & $\stackrel{\circ}{\frac{O}{4}}$ & $\frac{9}{4}$ \\
\hline & 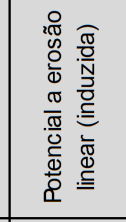 & $\frac{\mathrm{g}}{\mathrm{K}}$ & 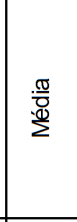 & 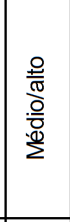 & $\begin{array}{l}\frac{0}{\mathrm{w}} \\
\frac{\mathrm{0}}{\overline{0}} \\
\frac{0}{2} \\
\end{array}$ & $\begin{array}{l}\frac{0}{0} \\
\frac{0}{0.0} \\
\frac{0}{2} \\
\frac{0}{2}\end{array}$ & $\begin{array}{l}\frac{.0}{0} \\
\frac{0}{2}\end{array}$ & 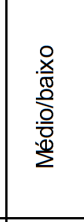 & 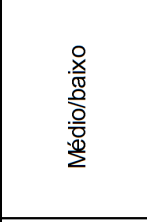 & 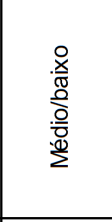 & 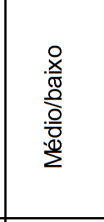 \\
\hline \multirow{4}{*}{ 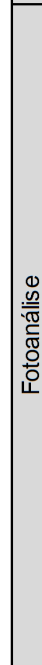 } & 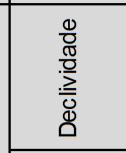 & 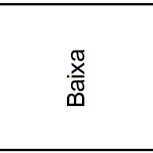 & 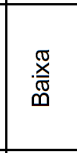 & 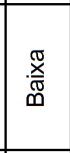 & $\begin{array}{l}\frac{.00}{0} \\
\frac{0}{20}\end{array}$ & 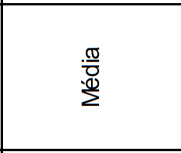 & $\begin{array}{l}\frac{.00}{0} \\
\frac{0}{2}\end{array}$ & $\begin{array}{l}\frac{.0}{0} \\
\frac{0}{2} \\
\end{array}$ & 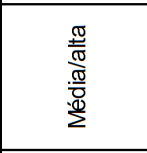 & $\frac{\mathrm{g}}{\mathrm{W}}$ & $\frac{\underline{W}}{\frac{\pi}{4}}$ \\
\hline & 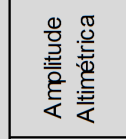 & 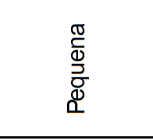 & $\begin{array}{l}\frac{0}{\overline{0}} \\
\frac{0}{20} \\
\end{array}$ & 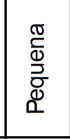 & $\begin{array}{l}\frac{0}{0} \\
\frac{0}{20} \\
\end{array}$ & $\begin{array}{l}\frac{0}{0} \\
\frac{0}{0} \\
\end{array}$ & 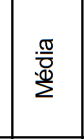 & $\begin{array}{l}\frac{0}{0} \\
\frac{\pi}{\pi} \\
\frac{\pi}{0}\end{array}$ & 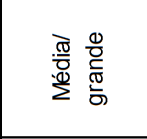 & $\begin{array}{l}\frac{0}{0} \\
\frac{\pi}{\pi} \\
\frac{\pi}{0}\end{array}$ & $\begin{array}{l}\frac{\pi}{0} \\
\frac{\pi}{\pi} \\
\frac{\pi}{0}\end{array}$ \\
\hline & 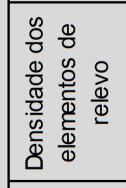 & 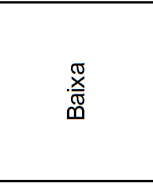 & 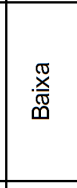 & 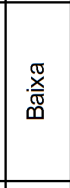 & 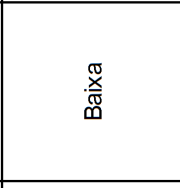 & $\begin{array}{l}\frac{0}{0} \\
\frac{0}{2} \\
\end{array}$ & $\begin{array}{l}\frac{.00}{0} \\
\frac{00}{2}\end{array}$ & $\begin{array}{l}\frac{\frac{\sigma}{0}}{0} \\
\frac{0}{2}\end{array}$ & $\frac{\widetilde{\sigma}}{4}$ & $\frac{\widetilde{w}}{4}$ & 要 \\
\hline & 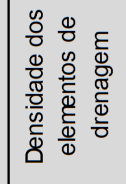 & 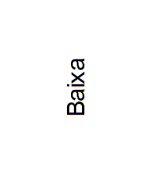 & 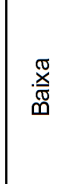 & 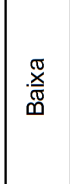 & $\begin{array}{l}\frac{0}{0} \\
\frac{0}{20}\end{array}$ & $\begin{array}{l}\frac{\sigma 0}{0} \\
\frac{0}{20}\end{array}$ & 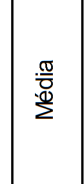 & $\begin{array}{l}\frac{.0}{0} \\
\frac{0}{20}\end{array}$ & 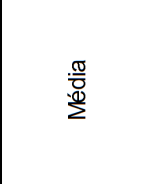 & $\frac{\mathbb{g}}{\mathbb{4}}$ & $\frac{\mathbb{g}}{<}$ \\
\hline \multirow[b]{2}{*}{ 离 } & 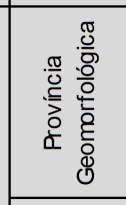 & 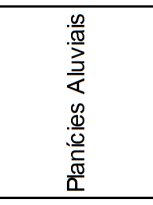 & 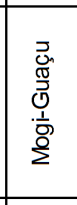 & 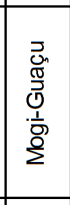 & 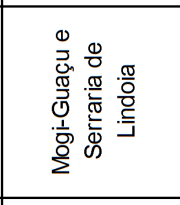 & 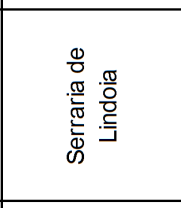 & 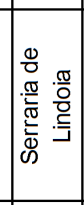 & 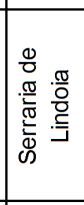 & 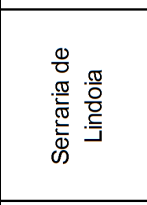 & 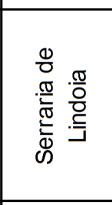 & 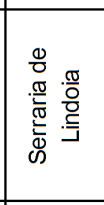 \\
\hline & 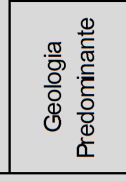 & 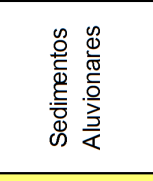 & 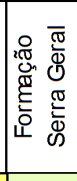 & 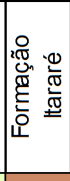 & 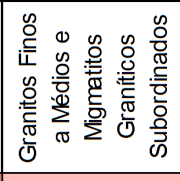 & 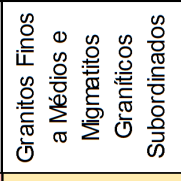 & 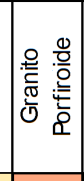 & 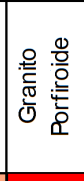 & 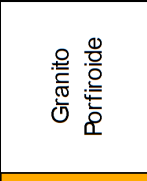 & 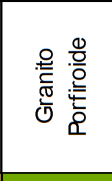 & 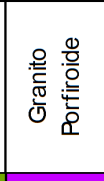 \\
\hline & 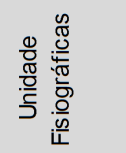 & $r$ & $N$ & $m$ & $\nabla$ & 10 & 0 & $\wedge$ & $\infty$ & $\sigma$ & 우 \\
\hline
\end{tabular}

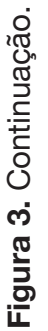



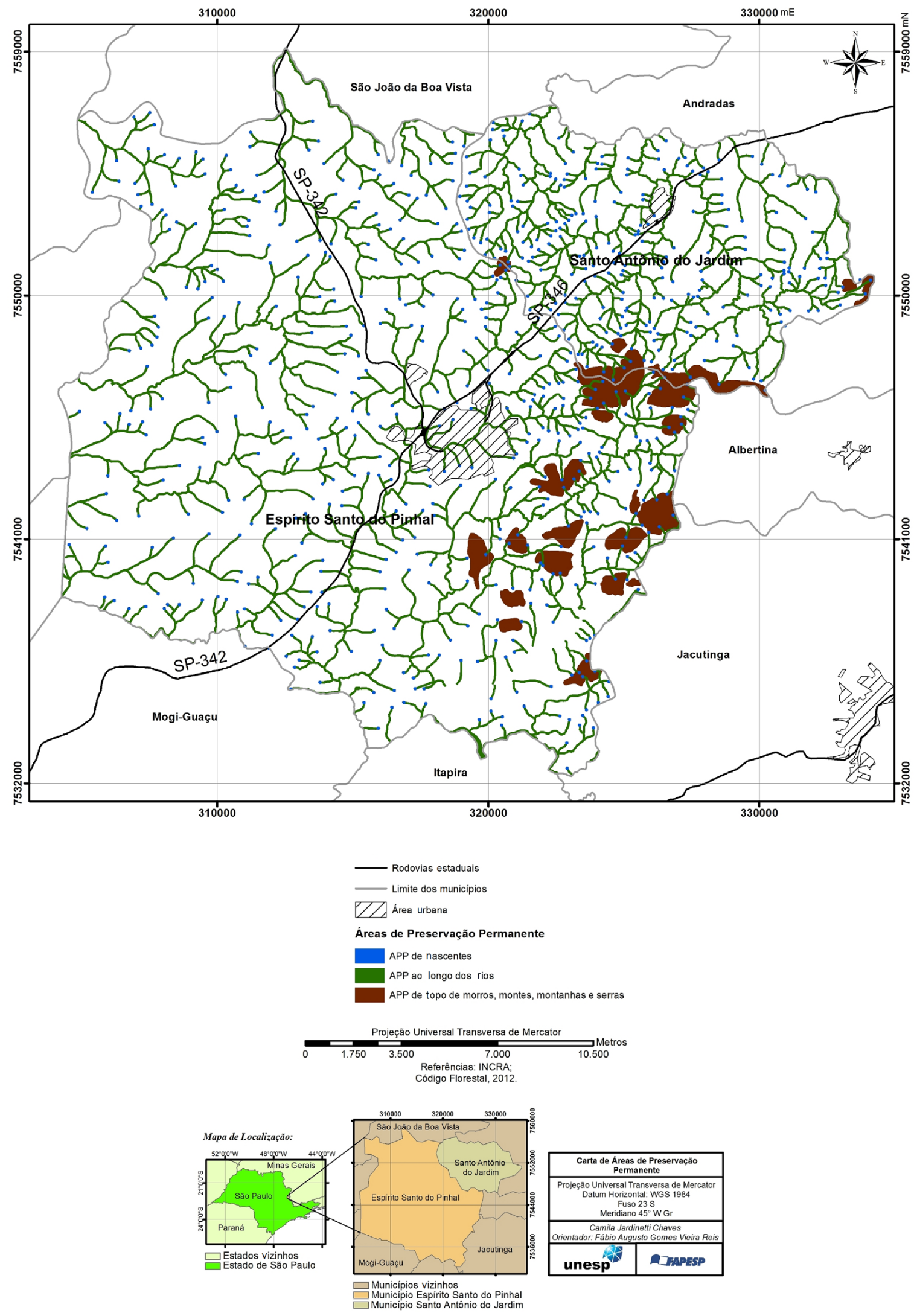

Figura 4. Carta de áreas de preservação permanente. 
superficial, já que o acúmulo de chuvas médias pode ser de 254,4 a $271,6 \mathrm{~mm}$, com suscetibilidade de alta a muito alta a chuvas intensas.

Recomenda-se, nessa subunidade geoambiental em relevo de morros com serras restritas, o levantamento de áreas de risco a movimentos de massa para a formulação de diretrizes de contenção e prevenção desses processos, bem como o incentivo a investimentos para a recuperação da vegetação nativa.

\section{Subunidade geoambiental F2}

Formada por sedimentos aluvionares compostos por areias, cascalhos e argilas inconsolidadas com baixa capacidade de suporte e nível de água subterrânea subaflorante, a subunidade geoambiental F2 apresenta áreas potenciais para a ocorrência de processos de erosão por solapamento das margens de drenagens, assoreamento, inundação e enchentes. Isso torna esses terrenos inadequados para a ocupação urbana.

Os usos e coberturas da terra atuais são: culturas temporárias $(31 \%)$, pastagem $(23 \%)$, vegetação arbórea $(17 \%)$ e vegetação arbustiva (12\%). O predomínio das culturas temporárias e das pastagens pode agravar ainda mais a potencialidade de ocorrência de assoreamento e erosões. Recomenda-se a formulação de diretrizes para medidas de contenção e prevenção desses processos, sobretudo nas planícies aluvionares localizadas na área urbana e a recomposição da mata ciliar.

\section{Unidade geoambiental G}

A unidade geoambiental $\mathrm{G}$ representa as áreas de preservação permanente de nascentes, ao longo de drenagens e topos de morros e montanhas com alta suscetibilidade a eventos climáticos intensos, podendo acumular mais de 271,6 mm de chuva em algumas áreas. Dessa forma, segundo o Código Florestal (Brasil, 2012), seu uso é restrito, dependendo de licenciamento prévio. São terrenos com grande potencial a ocorrência de processos de dinâmica superficial.

Atualmente essa unidade é ocupada por pastagem (27\%), cultura temporária $(23 \%)$, vegetação arbórea ( $17 \%)$, cultura permanente (15\%) e vegetação arbustiva (14\%). No entanto, as principais ocupações presentes relacionadas à pastagem e a cultura temporária não são recomendadas nessa unidade com alguns topos de morros e montanhas sem a cobertura da vegetação arbórea, no caso substituído por atividades agrícolas e silvicultura.

Recomendam-se levantamentos detalhados e delimitação das áreas de preservação permanente para evitar a supressão maior da vegetação nativa, incentivar a recomposição florestal e implantar medidas para a contenção do assoreamento ao longo das drenagens e dos processos erosivos nas encostas. A distribuição espacial das unidades geoambientais descritas anteriormente podem ser visualizadas na Carta de Unidades Geoambientais na Figura 7 e a legenda de cada unidade é apresentada na Tabela 8

\section{CONCLUSÕES}

Este trabalho visou o estudo do meio físico em busca de conhecer suas potencialidades e restrições de uso dos municípios de Espírito Santo do Pinhal e Santo Antônio do Jardim pela aplicação da compartimentação fisiográfica e abordagem multitemática na preparação de mapa geoambiental.

Pode-se concluir, pelos resultados obtidos, que a elaboração de um mapa geoambiental pode auxiliar de maneira considerável o planejamento urbano, sendo que a sequência metodológica usada na presente pesquisa pode ser desenvolvida com produtos cartográficos e imagens de uso público, sendo ideal para ser utilizada por município de pequeno e médio porte, pois apresenta custo baixo e aplicação relativamente fácil.

O uso da compartimentação fisiográfica pelo método de Zaine (2011) se mostrou adequado para integração das informações fisiográficas e geológicas da área de estudo, possibilitando a elaboração de um único produto cartográfico, sem a necessidade de preparar mapas geológicos e geomorfológicos na mesma escala, permitindo a análise integrada dessas informações mesmo com produtos cartográficos em escalas regionais.

Já o uso da abordagem multitemática se mostrou mais adequado para a integração de produtos cartográficos temáticos bem distintos na mesma escala, como as cartas de compartimentação fisiográfica de uso e cobertura da terra, chuvas intensas médias e áreas de preservação permanente, onde foram atribuídos pesos de prioridade para cada produto temático. Isso pode ser ajustado para diferentes realidades municipais. O AHP pode auxiliar na definição da ponderação, especialmente quando há uma equipe multidisciplinar envolvida no estudo, permitindo verificar a consistência na atribuição de pesos por diferentes especialistas, sendo de fácil aplicação, não envolvendo custos adicionais.

Na ponderação realizada na pesquisa, a carta de compartimentação fisiográfica teve o maior peso por se considerar que o comportamento do terreno é condicionado principalmente pelas características fisiográficas. Já as APP são áreas que naturalmente apresentam maior fragilidade e possuem restrições legais. Por este motivo, apresentou o segundo maior peso. As chuvas intensas médias e o uso e ocupação da terra tiveram pesos menores, especialmente, pelas características intrínsecas da área de estudo, por apresentar uma baixa variação pluviométrica e classes de uso e ocupação da terra ainda com baixo impacto, com grandes áreas preservadas e muitas culturas perenes, como café e silvicultura. 

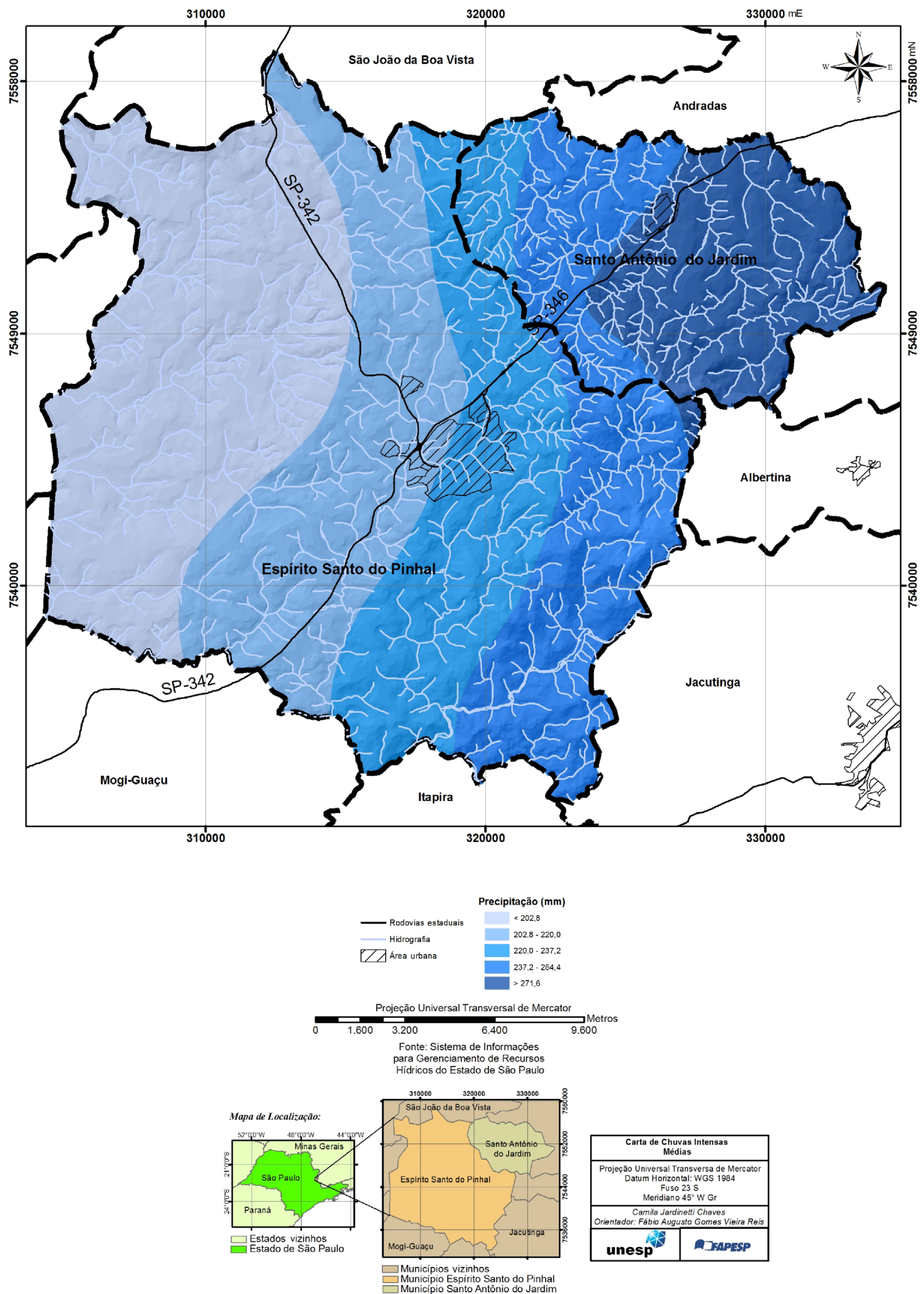

Figura 5. Carta de chuvas intensas médias. 

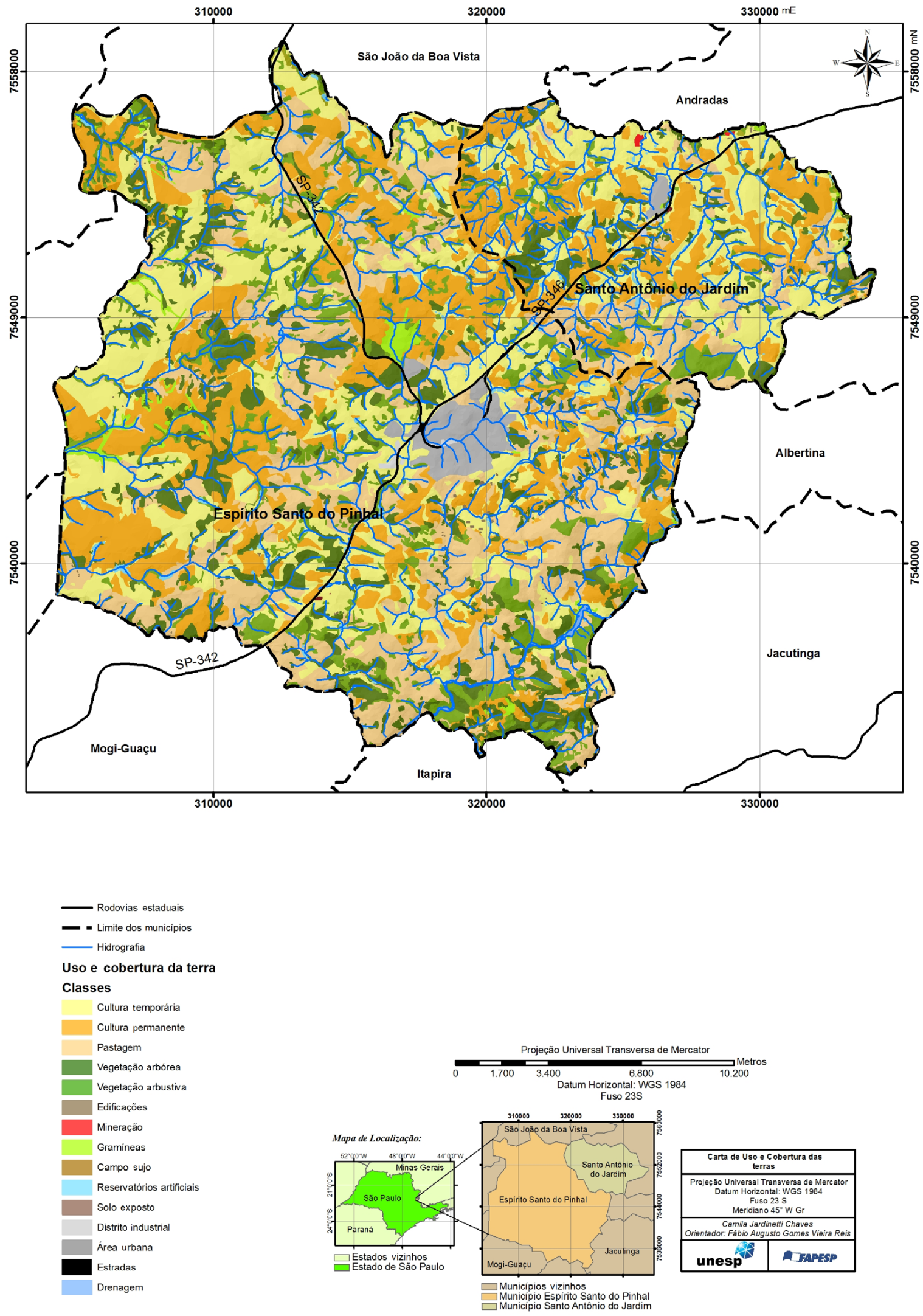

Figura 6. Carta de uso e cobertura da terra. 


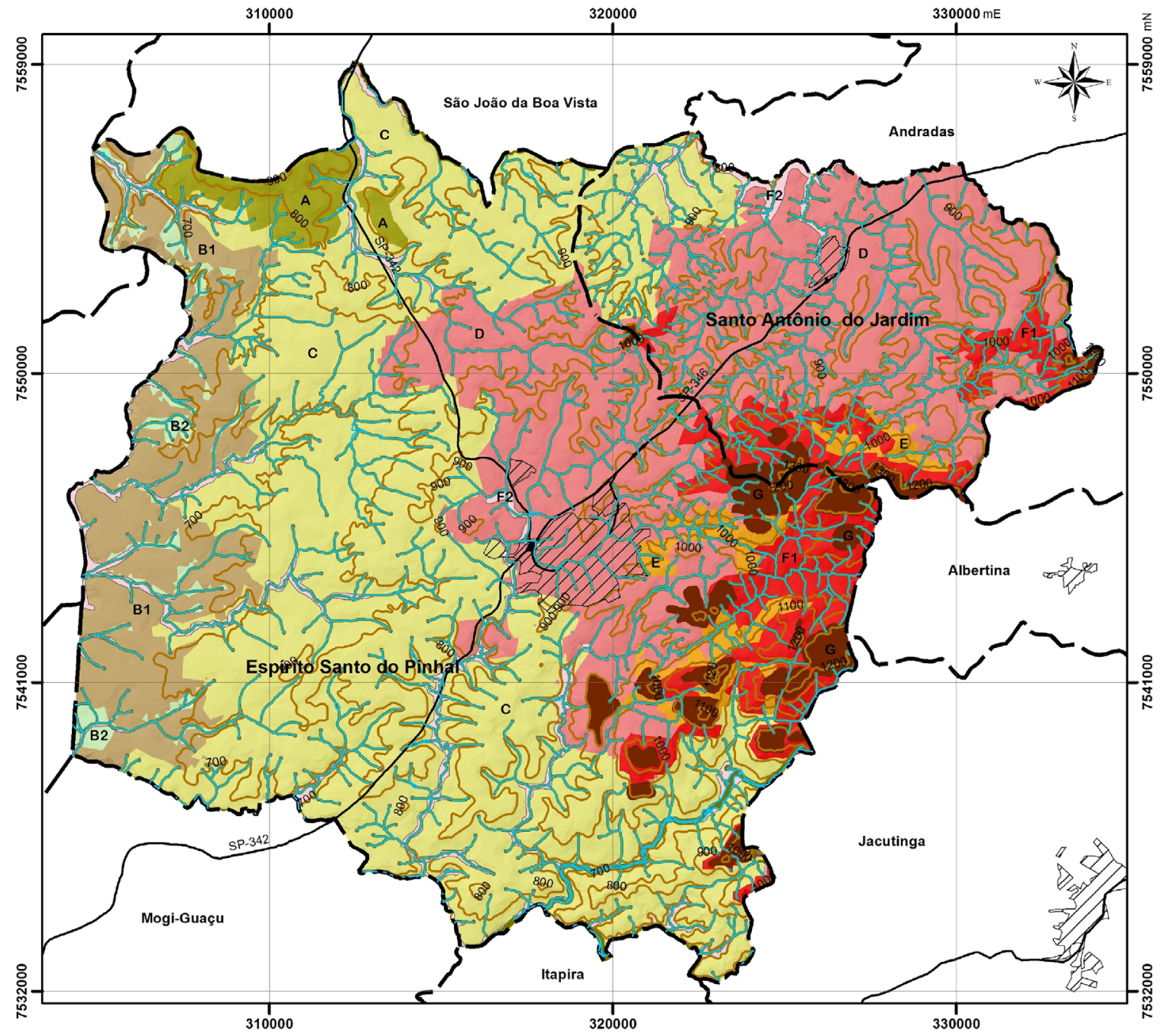

Convenções Cartográficas

पA Área urbana

- Hidrografia

- Rodovias estaduais

— Curvas de nível mestras

- - Limite de municípios

Projeção Universal Transversa de Mercator

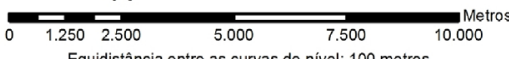

Equidistência entre as curvas de nivel: 100 metros
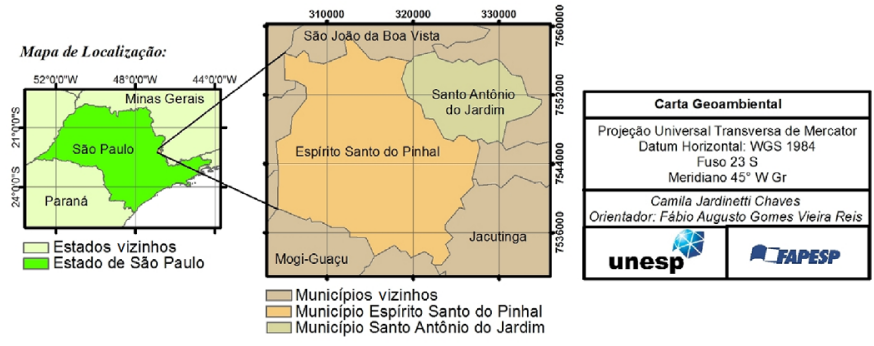

Figura 7. Carta de unidades geoambientais da área de estudo. 


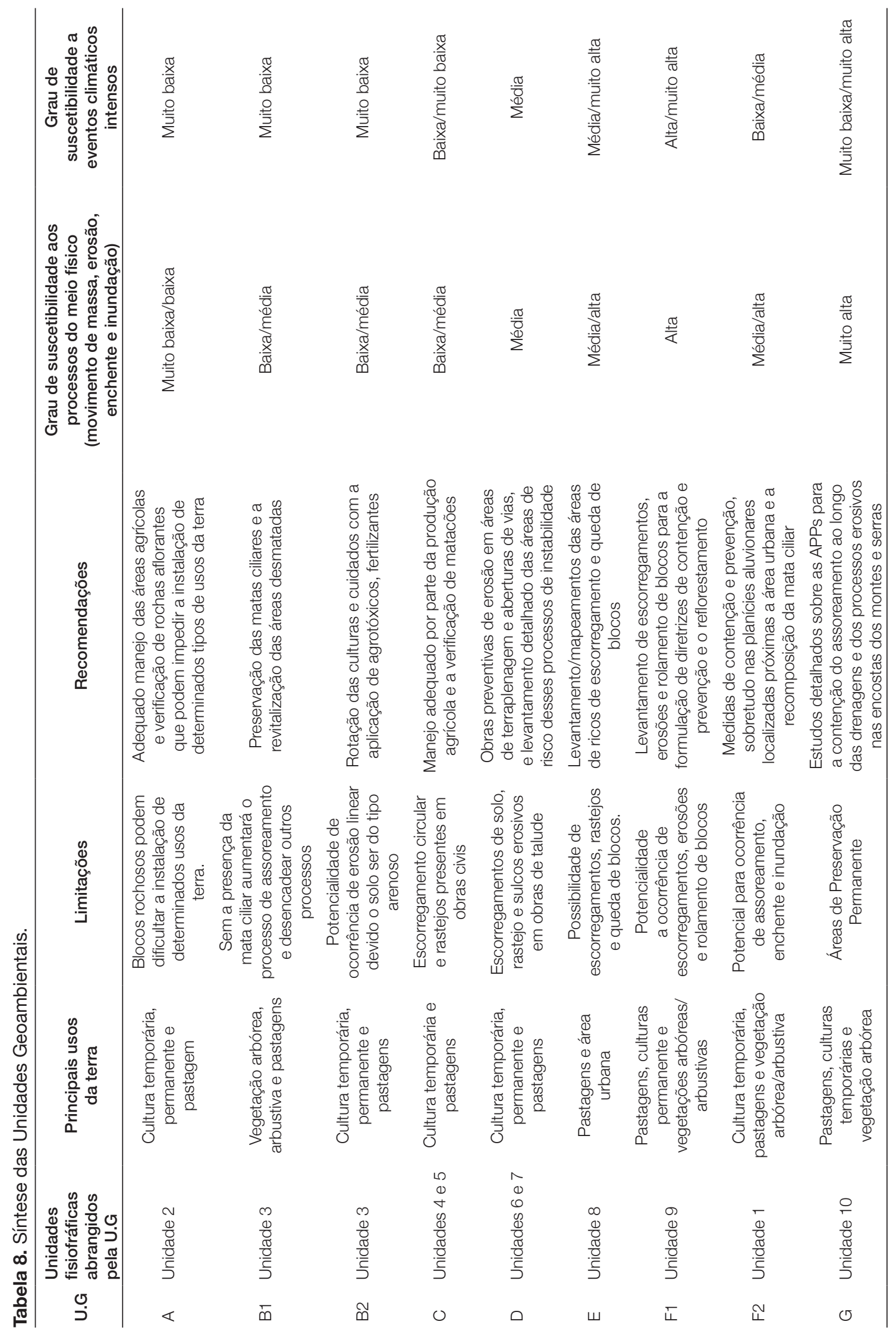


Para elaboração da Carta de Unidades Geoambientais houve a necessidade da aplicação de um filtro sobre as áreas pequenas e pouco representativas, sendo agrupadas aos polígonos vizinhos com maiores áreas, assumindo a mesma unidade geoambiental. Para que as áreas de preservação permanente fossem melhor representadas, houve a necessidade de colocá-las manualmente sobre a carta geoambiental, pois formaram uma única unidade geoambiental.

Quanto às características das imagens de satélite do Landsat TM 5, fornecidas gratuitamente pelo Instituto Nacional de Pesquisas Espaciais (INPE) e utilizadas na elaboração da carta de uso e cobertura da terra, pode ser citada como desvantagem a dificuldade de classificar os alvos e seus limites por serem imagens de média resolução e do ano de 2011.

Baseado nas informações da carta geoambiental, o mapeamento identificou e descreveu sete unidades geoambientais avaliadas quanto a adequação do uso e cobertura da terra. As características das unidades geoambientais A e das subunidades da B apresentaram-se com menor suscetibilidade aos processos de dinâmica superficial, sendo essas as unidades mais apropriadas para a mecanização agrícola e o desenvolvimento de culturas temporárias.

As unidades geoambientais C e D compreendem os terrenos mais adequados para a expansão urbana por conter relevo mais plano e também por abranger as cidades de Espírito Santo do Pinhal e Santo Antônio do Jardim. Medidas de controle para a minimização dos processos como rastejo, escorregamento circular e sulcos erosivos em obras de talude devem ser tomadas.

A unidade geoambiental $\mathrm{E}$ apresenta depósitos de tálus, sendo classificada com alta suscetibilidade aos processos de dinâmica superficial, devendo-se criar restrições para a expansão urbana nessas áreas.

A unidade geoambiental $\mathrm{F}$ foi dividida em duas subunidades, a F1 com cotas elevadas, podendo ocorrer movimentos de massa e processos erosivos, e a F2, associada a planícies aluvionares com potencialidade ao assoreamento, inundação e enchente. Em ambas devem ser realizadas constante práticas de manejo, criando restrições de uso e ocupação em áreas de risco.

A unidade geoambiental G representa as APP, onde o uso é restrito, voltado para a recuperação ambiental, sendo áreas com alta suscetibilidade a ocorrência de processos de dinâmica superficial, devendo ser destinada basicamente ao investimento do plantio de vegetação nativa.

Os resultados obtidos com esta pesquisa constataram que é possível o desenvolvimento de instrumentos de gestão ambiental, no caso a Carta de Unidades Geoambientais, de forma a evidenciar as potencialidades e fragilidades quanto ao uso da terra. Espera-se que os resultados obtidos nesta pesquisa possam ser utilizados como subsídio ao poder público dos dois municípios estudados, além de incentivar outros municípios de pequeno porte a criarem convênios para elaboração desse tipo de produto cartográfico que pode auxiliar no planejamento territorial.

\section{AGRADECIMENTOS}

Os autores agradecem a FAPESP (Processo 2013/03415-7) pelos auxílios financeiros que possibilitaram os trabalhos de campo e a bolsa de mestrado de Camila Jardinetti Chaves.

\section{REFERÊNCIAS}

Abreu, A. E. S., Augusto Filho, O. (2011). Engineering geological data in support of municipal land use planning: a case study in Analândia, southeast Brazil. Environmental Earth Science, 65, 277-289.

Azevedo, A. A. B., Massoli, M. (1984). Geologia da folha de aguaí, SP. Revista do Instituto Geológico, 5(1-2), 39-46. Acesso em 25 de janeiro de 2013, <http://ppegeo.igc.usp. br/pdf/rig/v5n1-2/v5n1-2a05.pdf $>$.

Bennett, M. R, Doyle, P. (1997). Environmental geology: geology and the human environment. Nova York: John Wiley \& Sons.

Brasil. Instituto Brasileiro de Geografia e Estatística (1972a). Mapa topográfico: Folha de Aguaí. Escala 1:50.000. São Paulo: IBGE. SF-23-Y-A-3-1.

Brasil. Instituto Brasileiro de Geografia e Estatística (1972b). Mapa topográfico: Folha de Águas de Lindoia. Escala 1:50.000. São Paulo: IBGE. SF-23-Y-A-III-4.

Brasil. Instituto Brasileiro de Geografia e Estatística (1972c). Mapa topográfico: Folha de Mogi Guaçu. Escala 1:50.000. São Paulo: IBGE. SF-23-Y-A-III-3.

Brasil. Instituto Brasileiro de Geografia e Estatística (1972d). Mapa topográfico: Folha de Pinhal. Escala 1:50.000. São Paulo: IBGE. SF-23-Y-A-III-2.

Brasil. Instituto Brasileiro de Geografia e Estatística (2010). Dados e informações sobre as cidades brasileiras com base nas pesquisas e censo realizado no ano de 2010. Acesso em 20 de outubro de 2012, <http://www.ibge.gov.br/cidadesat>.

Brasil. Lei $n^{\circ} 12.651$, de 25 de maio de 2012. Dispõe sobre a proteção da vegetação nativa; altera as Leis nos 6.938 , de 31 de agosto de 1981, 9.393, de 19 de dezembro de 1996, e 11.428, de 22 de dezembro de 2006; revoga as Leis nos 4.771 , de 15 de setembro de 1965, e 7.754, de 14 de abril de 1989, e a Medida 
Provisória no 2.166-67, de 24 de agosto de 2001; e dá outras providências. Acesso em 23 de junho de 2015, <http://www. planalto.gov.br/ccivil_03/_ato2011-2014/2012/lei/112651.htm>.

De Biasi, M. (1970). Cartas de declividade: Confecção e utilização. Geomorfologia, 21, 8-12.

Dewan, A. M., Yamaguchi, Y. (2009). Land use and land cover change in Greater Dhaka, Bangladesh: Using remote sensing to promote sustainable urbanization. Applied Geography, 29(3), 390-401.

Fernandes-da-Silva, P. C., Vedovello, R., Ferreira, C. J., Cripps, J. C., Brollo, M. J., Fernandes, A. J. (2010). Geo-environmental mapping using physiographic analysis: constraints on the evaluation of land instability and groundwater pollution hazards in the Metropolitan District of Campinas, Brazil. Environmental Earth Sciences, 61(8), 1657-1675.

Ferreira, C. J., Penteado, D. (2011). Mapeamento de risco a escorregamento e inundação por meio da abordagem quantitativa da paisagem em escala regional. XI Congresso Brasileiro de Geologia de Engenharia. São Paulo: ABGE. CD-ROM.

Fiori, A. P. (2004). Metodologias de Cartografia Geoambiental. $5^{\circ}$ Simpósio Brasileiro de Cartografia Geotécnica e Geoambiental. São Carlos: ABGE. CD-ROM.

Florenzano, T. G. (1998). Imagens TM-Landsat e HRV-SPOT na elaboração de cartas geomorfológicas de uma região do rio Taquari, MS. Pesquisa Agropecuária Brasileira, 33(n. esp.), 1721-1727.

Genderen, J. L. (1977). Testingland-use mapaccuracy. Photogrammetric engineering and remote sensing, 43(9), 1135-1137.

Ginevan, M. E. (1979). Testing land-use map accuracy: another look. Photogrammetric enginnering andremote sensing, 45(2), 167-176.

Giordano, L. C., Riedel, P. S. (2008). Multi-criteria spatial decision analysis for demarcation of greenway: a case study of the city of Rio Claro, São Paulo, Brazil. Landscape and Urban Planning, 84, 301-311.

Instituto de Pesquisas Tecnológicas de São Paulo (1981a). Mapa Geológico do Estado de São Paulo. Escala: 1:500.000. São Paulo: IPT.

Instituto de Pesquisas Tecnológicas de São Paulo (1981b). Mapa Geomorfológico do Estado de São Paulo. Escala: 1:1.000.000. São Paulo: IPT.
Instituto Geológico do Estado de São Paulo. (1983). Formações Geológicas de superficie: Folha Geológica Aguaí. Escala 1:50.000. São Paulo: IG. SF-23-Y-A-III-1.

Lepsch, I. P. (1983). Manual para levantamento utilitário do meio físico e classificação de terras no sistema de capacidade de uso: $4^{a}$ aproximação. Campinas: Sociedade Brasileira de Ciência do Solo.

Li, Y., Zhu, X., Sun, X., Wang, F. (2010). Landscape effects of environmental impact on bay-area wetlands under rapid expansion and development policy: a case study of Lianyungang, China. Landscape and Urban Planning, 94(3-4), 218-227.

Lollo, J. A. (1998). Caracterização geotécnica da área de expansão urbana de Ilha Solteira (SP) com o uso de formas de relevo. Simpósio Brasileiro de Cartografia Geotécnica, 3. Florianópolis: ABGE. CD-ROM.

Lopes, M. F. C. (1994). Condições de ocorrência de água subterrânea nas bacias dos rios Piracicaba e Capivari. Dissertação (Mestrado). Campinas: Faculdade de Engenharia Civil - UNICAMP.

Lousada, E. O., Campos, J. E. G. (2005). Integração de dados geológicos, geofísicos e de Sensoriamento Remoto para a locação de poços tubulares em aquíferos fraturados. Revista Geociências, 24(2), 173-180.

Oliveira, T. A., Riedel P. S.; Vedovello, R.; Souza, C. R. G.; Brollo, M. J. (2007). Utilização de técnicas de fotointerpretação na compartimentação fisiográfica do município de Cananeia, SP: apoio ao planejamento territorial e urbano. Revista Geociências, 26(1), 55-65.

Pilachevsky, T. (2013). Zoneamento geoambiental do municipio de São João da Boa Vista (SP). Dissertação (Mestrado). Rio Claro: Universidade Estadual Paulista - UNESP.

Ross, J. L. S. (1995). Análises e sínteses na abordagem geográfica da pesquisa para o planejamento ambiental. Revista do Departamento de Geografia, 9, 65-75.

Ross, J. L. S., Moroz, I. C. (1997). Mapa geomorfológico do Estado de São Paulo. Escala 1:500.000. São Paulo: Laboratório de Geomorfologia do Departamento de Geografia da Faculdade de Filosofia Letras e Ciências Humanas da Universidade de São Paulo.

Saaty, T. L. (1980). The analytic hierarchy process. Nova York: McGraw-Hill. 
Silva, C. R., Dantas, E. D. (2010). Mapas geoambientais. Departamento de Gestão Ambiental, Serviço Geológico do Brasil. Acesso em 7 agosto de 2012, <http://www.cprm.gov. $\mathrm{br} /$ publique/media/mapas_geoambientais_SCGG.pdf $>$.

Soares, P. C., Fiori, A. P. (1976). Lógica e sistemática na análise e interpretação de fotografias aéreas em geologia. Notícias Geomorfológicas, 32(6), 71-104. Acesso em 13 de setembro de 2012, <http://xa.yimg.com/kq/groups/25309279/3 63173872/ name/soares+\%26+fiori.pdf $>$.

Sparovek, G., Berndes, G., Klug, I. L. F., Barretto, A. G. O. P. (2010). Brazilian agriculture and environmental legislation: status and future challenges. Environmental Sciences \& Technology, 44, 6046-6053.

Valeriano, M. M. (2008). TOPODATA: guia para utilização de dados geomorfológicos locais. Instituto Nacional de Pesquisas Espaciais, Relatório INPE-15318-RPQ/818. 75p.

Vedovello, R., Mattos, J. T. (1993). Zoneamento geotécnico, por sensoriamento remoto, para estudos de planejamento do meio físico: aplicação em expansão urbana. VII Simpósio Brasileiro de Sensoriamento Remoto.

Vedovello, R., Mattos, J. T. (1998). A utilização de Unidades Básicas de Compartimentação (UBCs) como base para a definição de unidades geotécnicas: uma abordagem a partir de sensoriamento remoto. III Simpósio Brasileiro de Cartografia Geotécnica. Florianópolis: ABGE.

Vedovello, R., Brollo, M.J., Tominaga, L.K., Riedel, P.S., Cardoso, D., Terrell, D. (2002). Compartimentação fisiográfica do litoral norte do estado de São Paulo voltada para a avaliação de terrenos. X Congresso Brasileiro de Geologia de Engenharia e Ambiental. Ouro Preto: ABGE. CD-ROM.

Zaine, J. E. (2011). Método de Fotogeologia aplicado a estudos geológico-geotécnicos: ensaio em Poços de Caldas, MG. Tese (Livre docência). Rio Claro: Instituto de Geociências e Ciências Exatas - UNESP.

Zuquette, L. V., Gandolfi, N. (2004). Cartografia geotécnica. São Paulo: Oficina de Textos. 